Cómo citar este trabajo: Climent López, E.A., Lardiés Bosque, R., \& Esteban Rodríguez, S. (2022). Alternative economic practices at the local level in urban spaces: the case of Zaragoza (Spain). Boletín de la Asociación de Geógrafos Españoles, (92). https://doi.org/10.21138/bage.3041

\title{
Prácticas económicas alternativas de escala local en espacios urbanos: el caso de Zaragoza
}

Alternative economic practices at the local level in urban spaces: the case of Zaragoza (Spain)

\section{Eugenio Antonio Climent López \\ ecliment@unizar.es}

\section{Raúl Lardiés Bosque}

rlardies@unizar.es

\section{Samuel Esteban Rodríguez}

sestebanr@unizar.es

Departamento de Geografía y Ordenación del Territorio

Universidad de Zaragoza (España)

\section{Resumen}

En las últimas décadas, con más intensidad a raíz de la crisis del 2008, han proliferado algunas prácticas económicas alternativas al sistema dominante, especialmente en las áreas urbanas en que los nuevos movimientos sociales han tenido más arraigo. Se toma como estudio de caso la ciudad de Zaragoza, que estuvo gobernada en la pasada legislatura por una coalición de la nueva izquierda, siendo uno de los llamados ayuntamientos del cambio. Se han seleccionado prácticas que funcionan a escala local siguiendo procedimientos alejados de los convencionales: huertos urbanos comunitarios, mercados y grupos de consumo agroecológico, monedas 
comunitarias (banco de tiempo, mercados de trueque y moneda social) y centros sociales autogestionados. Se emplea una metodología cualitativa basada en entrevistas semiestructuradas, combinada con cuestionarios cerrados y observación participante. Dichas prácticas se localizan de modo disperso por todo el espacio urbano. Se han puesto en relación con los movimientos sociales urbanos y con la política local. Se concluye que su impacto es limitado en términos cuantitativos, pero que disponen de un amplio potencial transformador por las características de sus practicantes y el apoyo de la administración local.

Palabras clave: agroecología; monedas comunitarias; movimientos sociales urbanos; ayuntamientos del cambio.

\begin{abstract}
In recent decades, but more intensely as a result of the 2008 crisis, some economic practices alternative to the dominant economic system have proliferated, especially in urban areas where the new left-wing social movements have taken root. The city of Zaragoza is presented as a case study; having been governed in the last legislature by a coalition of the new left, is considered one of the so-called municipalities of change. Some practices have been selected that work on a local scale following procedures that are clearly different from the conventional ones: community urban gardens, agro ecological markets and consumption groups, community currencies -time bank, barter markets, local exchange trade systems- and self-managed social centers. A qualitative methodology based on semi-structured interviews, combined with surveys and participant observation has been used. These practices are located scattered throughout the urban space. They are related to urban social movements and local politics. It is concluded that their impact is limited in quantitative terms, but that they have broad transformative potential due to the characteristics of their practitioners and the support of local government.
\end{abstract}

Key words: agroecology; community currencies; urban social movements; municipalities of change.

\title{
1 Introducción
}

Se entiende por prácticas económicas alternativas (PEA) las que "se desarrollan de un modo diferente al de los dictados y convenciones de la corriente principal de la economía" (Leyshon \& Lee, 2003, p. 4), es decir, el capitalismo neoliberal, que a partir de la crisis económica de los años setenta del siglo XX supuso el retorno al supuesto liberal clásico de que el mercado es el 
mejor regulador de las actividades económicas. El estudio de dichas PEA ha conocido en la geografía y en otras ciencias sociales un desarrollo tan amplio que puede hablarse, siguiendo a Fickey y Hanrahan (2014), de un auténtico programa de investigación.

No existe una concepción única de qué pueda ser alternativo al sistema económico actual. Se identifican al menos tres posicionamientos: el primero es un anticapitalismo radical, que "denuncia la explotación, la depredación, la opresión, la exclusión y la desigualdad como procesos y efectos consustanciales al capitalismo y propugna la construcción de una economía dirigida a la satisfacción sostenible de las necesidades de todas las personas, no orientada hacia el lucro particular" (Sánchez Hernández, 2019, p. 19). El segundo es un reformismo preocupado por corregir los aspectos más dañinos del sistema, que "busca formas de vivir y redefinir un capitalismo consciente de los límites sociales y ecológicos y trata de ver cómo cambiar nuestros valores económicos para incluir el cuidado y el respeto a nuestras familias, comunidades y otros saberes y culturas" (Harcourt, 2014, p. 18-19). El tercero amplía el foco, "releyendo el paisaje económico del mundo occidental como un paisaje en gran parte no capitalista, integrado por una pluralidad económica" (White \& Williams, 2016, p. 1625).

Se han publicado algunos trabajos de catalogación y clasificación sistemática de PEA, de entre los que cabe destacar dos: uno de carácter más teórico-conceptual, publicado el año en que empezó la crisis de 2008 (Gibson-Graham, 2008, p. 617), y otro más orientado a la investigación empírica en el contexto de las ciudades españolas, publicado cuando la recesión había pasado ya (Méndez, 2015, p. 8). Uno y otro ofrecen perspectivas complementarias y tienen en común que enumeran y describen una amplia gama de PEA.

El primero de ambos trabajos establece seis grandes grupos: 1) prácticas centradas en el cuidado de otros y la provisión directa de bienestar material, como el trabajo en el hogar. 2) Cooperativas de consumo, producción y trabajo, organizadas sobre la base de la solidaridad, que distribuyen sus plusvalías entre sus miembros y la comunidad. 3) Movimientos que ponen en el centro de la actividad económica el cuidado del medio ambiente, los paisajes y las formas de vida, como el movimiento norteamericano Community Supported Agriculture. 4) Monedas locales y complementarias, donde se incluyen los Local Exchange Trading Systems, bancos de tiempo y mercados de trueque. 5) El "tercer sector", integrado por cooperativas, mutualidades, organizaciones de voluntariado, fundaciones y otras actividades sin ánimo de lucro. 6) Redes informales de financiación, de alcance internacional, que facilitan directamente créditos o donaciones, como las remesas de los emigrantes a sus países de origen. Esta relación muestra 
una gran cantidad de prácticas orientadas a la satisfacción de las necesidades humanas - prácticas económicas, por tanto- que funcionan con valores distintos a los dominantes en el sistema capitalista e incluso al margen de los mecanismos del mercado.

El segundo de los trabajos citados clasifica las PEA en cuatro grupos: 1) prácticas de producción de bienes y servicios: redes de productores agroecológicos, huertos urbanos comunitarios, empresas de economía social, espacios de trabajo en común, cooperativas de trabajo asociado, cooperativas de vivienda y cooperativas de comunicación. 2) Prácticas de intercambio: bancos de tiempo, bancos de semillas, redes de trueque, mercados de productores y mercados de reciclaje. 3) Prácticas de consumo: grupos de consumo agroecológico, cooperativas de consumo, viajes compartidos, centros sociales y culturales, educación peer to peer, universidades populares o libres, cooperativas culturales y viviendas colectivas. 4) Prácticas de financiación: monedas alternativas y sociales, cooperativas locales de crédito. Esta relación muestra que las PEA se insertan en todas las fases del circuito económico.

La literatura geográfica pone el acento en que "cuando se intenta construir prácticas no capitalistas, la escala importa" (North, 2005, p. 221). Las PEA enumeradas se diferencian por la escala o ámbito espacial en que se desenvuelven. Algunas lo hacen a escala global o internacional: es el caso, por citar algunos ejemplos, de las redes que canalizan las remesas de los emigrantes, de las redes de economía colaborativa que a través de plataformas digitales operan en el espacio virtual o de las fundaciones del tercer sector y las organizaciones no gubernamentales que operan en diversos países. Otras, por el contrario, tienen un alcance meramente local, como los Local Exchange Trading Systems o los huertos urbanos comunitarios.

Otro aspecto crucial en el que insiste la investigación geográfica es hasta qué punto las PEA se distancian de los modelos capitalistas de comportamiento económico (Zademach \& Hildebrand, 2013). Se observa que algunas asumen plenamente las reglas del mercado, aun cuando se guíen por valores distintos de los del capitalismo; es el caso de las entidades de economía social -cooperativas de producción, por ejemplo- que se comportan en los mercados igual que las empresas convencionales, pero tienen una forma de remunerar el trabajo de los socios o distribuir beneficios basada en valores y criterios más sociales que económicos. Es también el caso de la agricultura ecológica, cada vez más integrada en los circuitos comerciales convencionales, aun cuando en ella los valores de respeto y cuidado del medio ambiente estén por encima de la mera obtención de un beneficio económico. Otras PEA, por el contrario, 
rechazan de plano los mecanismos del mercado e incluso el propio dinero; es el caso de los bancos de tiempo o los grupos de consumo agroecológico.

Por tanto, cabe considerar en las PEA dos dimensiones, una espacial y otra funcional, en cada una de las cuales pueden establecerse criterios de proximidad: en el primer caso esta viene definida por la escala de actuación de la PEA -desde la local a la global- y en el segundo por su grado de similitud con las prácticas económicas capitalistas -desde la plena aceptación de los mecanismos del mercado hasta el rechazo de estos.

Este artículo centra la atención en las PEA que presentan el mayor grado de proximidad espacial y el menor grado de proximidad funcional, es decir, las que operan exclusivamente a escala local y funcionan según procedimientos muy alejados de los de las prácticas económicas capitalistas.

Estas PEA surgen en las décadas finales del siglo XX, en el seno de movimientos sociales críticos de las políticas neoliberales, pero han adquirido nuevo impulso a raíz de la crisis de 2008 y las medidas gubernamentales puestas en práctica para salir de ella: "Especialmente en la periferia europea la combinación de austeridad y políticas neoliberales de privatización y desregulación han llevado a la incapacidad de los gobiernos para atender las demandas de los ciudadanos en orden a salvaguardar la democracia y sus derechos" (Kousis \& Paschou, 2017, p. 146). Esto ha dado lugar a nuevos movimientos sociales de base y nuevos partidos políticos. En España dichos movimientos convergieron en el llamado $15 \mathrm{M}$, que tuvo como repercusión política directa la creación de un nuevo partido y nuevas coaliciones, que en las elecciones locales de 2015 consiguieron las alcaldías de algunas grandes ciudades: Madrid, Barcelona, Valencia, Zaragoza, Cádiz, La Coruña, Santiago de Compostela y Ferrol. Se les conoció como los "ayuntamientos del cambio". ${ }^{1}$

A partir de las reflexiones previas se concretan los objetivos de este trabajo: identificar y analizar el funcionamiento de PEA de escala local que se encuentran alejadas de la operativa económica convencional; establecer su relación con los movimientos sociales de base; definir y valorar sus

1 Las elecciones locales de mayo de 2019 alteraron posteriormente ese panorama: la agrupación electoral Madrid en Común fue la más votada, pero el gobierno municipal pasó al Partido Popular, en coalición con Ciudadanos. Zaragoza en Común sufrió una fuerte pérdida de votos y el gobierno pasó a la misma coalición que en Madrid. Similar pérdida se produjo en las tres ciudades gallegas, cuyo gobierno pasó al Partido Socialista Obrero Español. No obstante, siguen gobernando los mismos alcaldes, apoyados en las mismas coaliciones electorales, en Barcelona, Valencia y Cádiz. 
formas de inserción en las políticas locales y su integración en el espacio urbano. La escala local de dichas prácticas aconseja adoptar como método de trabajo el estudio de caso.

Se han publicado diversos estudios de caso sobre las PEA existentes en algunos "ayuntamientos del cambio", como Madrid (Gonick, 2016; Michelini et al., 2017; Méndez \& Monteserín, 2019; Méndez, 2018), Barcelona (Conill et al., 2012; García et al., 2015; Yates, 2015; Fernández \& Miro, 2016) y Valencia (Salom et al., 2017; Salom et al., 2019), pero también sobre otras

ciudades donde no han gobernado las nuevas agrupaciones electorales, como Valladolid (Pascual et al., 2018), Oviedo (López \& Benito, 2019), León (Benito \& López, 2019) y Salamanca (Sánchez et al., 2017). A ellos hay que añadir algunos estudios comparativos (Subirats \& García, 2015; Díaz et al., 2018; González \& Torres, 2019; Sánchez \& Glückler, 2019). Para el presente estudio de caso se ha elegido Zaragoza, una ciudad en la que los nuevos movimientos sociales tuvieron el suficiente arraigo y fuerza como para acceder al gobierno municipal y que no ha sido objeto de ningún trabajo monográfico, aunque sí está incluida en el ya citado de González \& Torres (2019).

El trabajo se organiza de la siguiente manera: en el apartado segundo se perfila el marco teórico a partir del cual se conceptualizan las PEA de alcance local y su vinculación con los movimientos sociales de base. En el apartado tercero se explica la metodología utilizada. A continuación se presentan los resultados: cómo funcionan las PEA identificadas en la ciudad, qué relación tienen con los movimientos sociales y con el gobierno local y cómo se integran en el espacio urbano. Finalmente se discuten los resultados y se exponen las conclusiones.

\section{Prácticas económicas alternativas de ámbito local: por una ciudad más solidaria y un mundo más sostenible}

A partir de la bibliografía disponible, especialmente los ya comentados trabajos de GibsonGraham (2008) y Méndez (2015), se han podido identificar y seleccionar un conjunto de PEA que operan a escala local y funcionan según procedimientos muy alejados de los mecanismos del mercado. En primer lugar cabe señalar las que tienen que ver con la agroecología, movimiento social que a los valores ecológicos de respeto al medio ambiente añaden otros emparentados con el comercio justo y la proximidad espacial. En segundo lugar están las denominadas genéricamente monedas comunitarias, que tienen que ver con el intercambio de bienes y servicios, siendo su principal característica el rechazo al dinero de curso legal. En tercer lugar, los centros sociales autogestionados, donde, de forma gratuita, se prestan servicios 
de carácter cultural, se gestionan proyectos comunitarios y se realizan tareas de reivindicación social y concienciación política.

\subsection{Prácticas agroecológicas}

La agroecología surgió a raíz de la crisis económica de los años setenta del siglo XX y puede definirse como "un movimiento social que atraviesa los territorios urbanos y rurales, y que se desarrolla tanto en el Norte como en el Sur globales, hacia la sostenibilidad y la equidad en el sistema agroalimentario" (López García, 2015, p. 32). Abarca las tres fases del circuito económico de los alimentos - la producción, el comercio y el consumo- bajo los principios de la sostenibilidad y el respecto al medio ambiente. La proximidad espacial se concreta en el consumo de alimentos producidos localmente, pues evitar el transporte a largas distancias es una de las claves del ahorro de energía y, por tanto, de la sostenibilidad ambiental. Se organizan mediante el contacto directo entre productores y consumidores, al margen de los canales comerciales convencionales. Además incorporan los valores del comercio justo, es decir, la garantía de que el precio que recibe el productor cubre los costes de producción, aunque los precios de mercado sean inferiores. Se han identificado y seleccionado tres PEA concretas: los huertos urbanos comunitarios, los mercados agroecológicos y los grupos de consumo.

El movimiento de los huertos urbanos comunitarios surgió a raíz de la crisis de los setenta, destacando las Green Guerrillas de Nueva York, nacidas como reacción frente al deterioro del espacio urbano subsecuente al abandono de solares por la crisis. Los fundadores "centraron su atención en una amplia parcela libre llena de escombros en la esquina de las calles Bowery y Houston. Donde otra gente veía una parcela libre ellos vieron un huerto comunitario. La gente donó su tiempo y su talento. Algunas tiendas y guarderías locales regalaron esquejes y semillas de verduras. Así crearon la Granja y Huerto Bowery Houston e iniciaron un movimiento" (Green Guerrillas, 2019). Actualmente hay 600 huertos comunitarios en la ciudad de Nueva York y el fenómeno se ha extendido ampliamente por el mundo.

En España este movimiento social empezó bastante más tarde. Asociado en sus orígenes al movimiento vecinal, a partir de 2011 adquiere mayor relevancia, impulsado por el movimiento 15M (Gómez, 2019, p. 89).

A partir de los años setenta del siglo XX proliferan los mercados agroecológicos, con el objetivo de potenciar las formas de producción ecológicas y el contacto directo entre productores y consumidores. En cierto modo son continuadores de los mercados urbanos tradicionales, ubicados en plazas al aire libre, en los que los agricultores del entorno vendían sus productos; 
estos mercados fueron desapareciendo, aunque algunos han mostrado una notable persistencia, como los farmers' markets británicos (Kirwan, 2006) o algunos españoles (Mauleón Gómez, 2012).

Los mercados agroecológicos surgieron en España en los años anteriores a la última crisis, pero es a partir de 2011, tras el 15M, cuando han alcanzado mayor desarrollo. La iniciativa normalmente ha sido de las asociaciones agrarias y de los productores (Espinosa Seguí et al., 2020). Los gobiernos locales, por su parte, se han situado entre el apoyo decidido y una escasa sensibilidad (Méndez \& Monteserín, 2017, p. 201).

En el contexto del movimiento agroecológico se ha producido la eclosión de grupos de consumo, integrados normalmente por unas pocas familias que se coordinan para comprar directamente a productores. En España han tenido una rápida expansión desde principios de siglo. El impulso inicial tuvo que ver con la dificultad de conseguir alimentos ecológicos, pues solo los ofrecían algunas tiendas, con escasa oferta. Así es como se "comenzaron a formalizar comunidades unidas por el consumo que les permitieran generar una demanda suficiente y estable para conseguir que los productores locales les proveyeran con alimentos agroecológicos" (Espinosa Seguí, 2019, p. 68). Este problema ya no existe, pues han proliferado las tiendas especializadas y hasta las empresas de grandes superficies comerciales ofrecen productos ecológicos, pero los grupos siguen activos, porque sus socios conceden gran importancia a la relación directa con los productores, por la confianza que genera el trato personal continuado. Contribuyen al sostén de las formas de producción ecológicas, pues dan seguridad a los agricultores mediante sus pedidos regulares a precio justo. En este sentido

entroncan con movimientos extendidos en numerosos países, como la Community Supported Agriculture de Estados Unidos, en la que consumidores y productores comparten los riesgos económicos de la producción; ejemplo de esta agricultura con apoyo comunitario en España es la asociación "Bajo el Asfalto está la Huerta" de Madrid (López García, 2015, p. 62; Michelini et al., 2017, p. 685).

\subsection{Monedas comunitarias}

Las monedas comunitarias son un conjunto de prácticas de intercambio de bienes y servicios que usan medios de pago distintos de las monedas de curso legal (Rice, 2014).

La más simple de las tres es el trueque, forma de intercambio de bienes anterior al uso de la moneda, que sigue estando vigente en diversos contextos: "pudimos observar que el trueque ha estado presente a lo largo de la historia, y se ha transformado y resignificado en función de los 
desafíos que el propio entorno ha ido generando. Se trata pues de una práctica histórica que gracias a su dinamismo se mantiene vigente hoy día" (Argueta \& Cortez, 2016, p. 89-90). Pueden revestir notable importancia en circunstancias y ámbitos geográficos en que la moneda legal escasea o no circula bien. El mayor ejemplo es la "Red Global de Trueque", fundada en Argentina en 1995, que es una red de usuarios organizados en clubes de trueque para llevar a cabo intercambios seguros en un momento en que la moneda oficial tenía un comportamiento caótico (Sanz Casas, 2002). La iniciativa sigue viva, con altibajos: normalmente crece en épocas de crisis y decrece en las de bonanza.

Los bancos de tiempo son sistemas de intercambio de servicios, cuya unidad contable es el tiempo empleado. A diferencia del trueque, los intercambios no se realizan persona a persona, sino mediante acuerdos multilaterales, garantizados por un órgano gestor, que hace de intermediario, abonando y cargando, según corresponda, en la cuenta de cada usuario las horas empleadas en la prestación de los servicios. Los socios deben tener un saldo equilibrado a medio plazo (Pariza et al., 2014; Sanz, 2002).

Dedicar una parte del tiempo personal a ayudar a los vecinos ha sido una práctica habitual a lo largo de la historia. La formalización de la misma en bancos de tiempo se produjo en la década de 1980 en Estados Unidos. La iniciativa fue de Edgar Cahn, que la explica así: "quienes desarrollamos el banco de tiempo quisimos mostrar que junto al dólar podía existir una clase diferente de moneda. Rehusamos dar al dinero el monopolio en la definición del valor. El sistema de mercado basado en el dinero no recompensa muchos tipos de trabajo crucial y creímos que debería haber una forma de honrar y recompensar esta clase de trabajo" (Cahn \& Gray, 2015, p. 41). Esos tipos de trabajo crucial a que se refiere el texto citado son: criar niños sanos, construir familias fuertes, cuidar de los mayores, revitalizar los barrios, preservar el medio ambiente, hacer avanzar la justicia social y sustentar la democracia.

El primer banco de tiempo de España se fundó en Barcelona en 1998 y le siguieron otros, ligados al movimiento vecinal, normalmente con el apoyo institucional de los ayuntamientos. Pero es a partir de la crisis del 2008 y del 15M cuando se incrementa notablemente su número.

Los Local Exchange Trading Systems (LETS) son redes de ayuda mutua basadas en la comunidad local que utilizan como unidad de cambio una moneda propia. Ello permite el intercambio combinado de bienes y servicios. Se trata de una iniciativa desarrollada a ambos lados del Atlántico desde finales de los ochenta (Sanz, 2002). En España se les denomina "monedas sociales" y pueden definirse como sistemas monetarios creados al margen de las monedas 
oficiales del país con el objetivo fundamental de promover proyectos de carácter local y poner en valor activos y recursos locales que a menudo se encuentran fuera de los circuitos económicos convencionales (Caravaca \& González, 2019, p. 3). Tienen el mismo fundamento fiduciario que las monedas oficiales, pero están ligadas siempre a los intercambios de bienes y servicios.

Las monedas sociales llegaron a España a partir de la crisis de 2008: "La mayoría de ellas nacen, pues, coincidiendo con los años en los que se hacían palpables los efectos de la crisis y, en muchos casos, fueron promovidas por las asambleas de barrios o municipios creadas a raíz del 15M" (González et al., 2019, p. 112).

Las monedas comunitarias, en resumen, se alejan radicalmente de las prácticas económicas convencionales porque usan medios de pago distintos del dinero de curso legal. Son PEA de escala local, pues la naturaleza de los intercambios, tanto de bienes como de servicios, así lo exige.

Las monedas comunitarias son herramientas innovadoras para el desarrollo de la comunidad (Mauldin, 2015) y medios adecuados para la construcción colectiva de una cultura alternativa, pudiendo ser jalones de un itinerario para ir afianzando una comunidad: primero los mercadillos de trueque, luego los bancos de tiempo y finalmente la moneda social (Llobera, 2013).

Los poderes locales mantienen actitudes diferentes ante este tipo de prácticas: en unos casos indiferencia o tolerancia; en otros apoyo y promoción. Algunos ayuntamientos han creado monedas propias -como el "Recurso Económico Ciudadano" de Barcelona (REC Moneda Ciutadana, 2019)- pero sin la pretensión de que sean alternativas a la oficial, sino complementarias; normalmente están concebidas como instrumento para llevar a cabo ciertas políticas municipales, como potenciar el comercio de proximidad u otras.

\subsection{Los centros sociales autogestionados: prestación de servicios socioculturales y alojamiento de prácticas económicas alternativas}

Estos centros son una concreción de diversos movimientos sociales que se oponen al sistema desde presupuestos marxistas, anarquistas y feministas. Se les asocia normalmente con el movimiento okupa porque muchos Centros Sociales Autogestionados (CSA) se ubican en edificios públicos vacíos y abandonados durante mucho tiempo, que fueron ocupados y acondicionados para "el desarrollo de actividades o funciones de utilidad pública que van desde centros para la creación de autoempleo, tratamiento de toxicómanos, asesorías jurídicas, a la animación sociocultural" (Dieste \& Pueyo, 2003). Estos servicios se ofrecen de manera 
gratuita, evitando cualquier tipo de transacción mercantil y favoreciendo el trabajo voluntario en favor de la comunidad.

El movimiento okupa se ha desarrollado en numerosos países como una forma de lucha social frente a la especulación urbana en todas sus formas. ${ }^{2}$ En España comenzó a mediados de los ochenta, siendo 1996 un punto de inflexión "puesto que es cuando entra en vigor el nuevo Código Penal que incrementa ostensiblemente el castigo a la ocupación y, al mismo tiempo, porque es el año en el que se inaugura la mayor visibilidad mediática del movimiento" (Martínez, 2003). A partir de 2011 se produce una convergencia con el movimiento 15M: en este participaron integrantes del movimiento okupa, produciéndose una nueva oleada de ocupaciones en numerosas ciudades (González et al., 2018).

Los CSA se desenvuelven a escala de ciudad o, más frecuentemente, de barrio. Su lejanía respecto a las prácticas económicas convencionales queda de manifiesto en la gratuidad de los servicios que ofrece y en la voluntariedad del trabajo de quienes los prestan. En el caso de los ubicados en edificios ocupados, la lejanía es aún mayor, pues implica una forma de ver la propiedad distinta de la convencional: los edificios públicos son un bien común y, por tanto, pueden ser utilizados libremente por la comunidad, al margen de las instituciones públicas que detentan la propiedad legal de los mismos.

Recapitulando, las siete PEA seleccionadas constituyen ejemplos de prácticas que se desarrollan a escala local y que operan de un modo muy diferente al de la economía convencional, como atestiguan su opción por los alimentos de proximidad y el comercio justo, su rechazo al dinero de curso legal, la gratuidad de los servicios y la gestión comunitaria de los edificios públicos. Estas prácticas son desarrolladas por movimientos sociales que impulsan la sostenibilidad ambiental y la solidaridad social, valores que no se hallan en el centro del sistema capitalista, al que dichos movimientos cuestionan en mayor o menor grado, desde la confrontación radical del movimiento okupa a la búsqueda de una complementariedad, como plantea Cahn en su filosofía de los bancos de tiempo. El hecho de que estas prácticas existan desde hace décadas en los países capitalistas avanzados, con especial arraigo en las ciudades, así como su revitalización desde la crisis de 2008, justifican plenamente que se les dedique un estudio en profundidad.

2 En este trabajo se hace referencia exclusivamente a la ocupación de edificios públicos para los fines sociales indicados. La ocupación de viviendas tiene otras connotaciones que no tienen que ver con las PEA. 


\section{Metodología}

La primera tarea llevada a cabo en este estudio de caso ha sido la identificación y localización de las prácticas agroecológicas, monedas comunitarias y centros sociales autogestionados existentes en Zaragoza, mediante una búsqueda sistemática por palabras clave en Internet. La práctica totalidad de las PEA de este tipo tiene una página web, individual o colectiva, de la que se han tomado los datos de contacto, las estadísticas disponibles e información sobre proyectos y actividades. No obstante, la mayor parte de la información ha sido obtenida directamente por el equipo de investigación, mediante técnicas cualitativas y cuantitativas.

La técnica cualitativa utilizada sistemáticamente ha sido la entrevista semiestructurada. Una vez establecido contacto con las PEA seleccionadas y obtenida su conformidad, se entrevistó a sus responsables directos a partir de un guion abierto. Las entrevistas fueron grabadas y posteriormente transcritas. El guion contenía preguntas sobre: creación, evolución y situación actual de la PEA; organización y gestión; actividades desarrolladas; beneficios obtenidos por los participantes; problemas y perspectivas de futuro; ámbito territorial de actuación y relación con otras PEA.

Se realizaron 11 entrevistas, distribuidas entre todos los tipos de PEA (Tabla 1), constituyendo una muestra representativa de las existentes en Zaragoza. En los casos del mercado agroecológico, el banco de tiempo y la moneda social, PEA de las que existe una sola en la ciudad, se ha entrevistado a las personas responsables de cada una. Existen 13 grupos pequeños de consumo agroecológico, integrados en una red, y una cooperativa de mayor tamaño; se ha realizado una entrevista al gerente de esta y otra al coordinador de la red. Los mercados de trueque disponen de una red de información, a cuya coordinadora se ha entrevistado. De los 6 grupos de huertos urbanos comunitarios se ha entrevistado a los responsables de cuatro de ellos. ${ }^{3}$ Finalmente, se han mantenido reuniones con grupos de socios -así lo decidieron ellos, en vez de designar un interlocutor único- en dos de los tres centros sociales autogestionados.

La técnica cuantitativa empleada ha sido la encuesta a los participantes en las PEA. Los cuestionarios incluían preguntas sobre su perfil sociodemográfico, su valoración del sistema económico actual y sobre aspectos concretos de cada PEA. Los cuestionarios fueron

3 En una entrevista se conversó con dos personas, responsables conjuntamente de dos grupos de huertos urbanos. 
cumplimentados en línea y en papel. Los responsables de las PEA actuaron como facilitadores, distribuyendo entre sus socios el cuestionario.

Las cifras de participantes en las PEA (Tabla 1) corresponden a aquellas cuyos responsables han sido entrevistados. Disponen de registro de socios el banco de tiempo, los huertos urbanos, el mercado agroecológico, la cooperativa de consumo y uno de los centros sociales autogestionados, por lo que sus cifras pueden considerarse altamente fiables. Respecto a la red de trueque, la cifra es una estimación de los asistentes al último mercado que se ha celebrado, hecha por la persona entrevistada. La cifra de los grupos de consumo está calculada a partir de la información parcial que ofrece la página web de la red. La moneda social no está operativa, por lo que actualmente no hay participantes. Se han obtenido en total 96 cuestionarios: 84 a través de la aplicación en línea y 12 en papel. El tamaño de la muestra así obtenida es suficiente para un nivel de confianza de entre el 91\% y el 92\%; aunque su representatividad no es óptima, existe la garantía de una fiabilidad razonable de los resultados.

Tabla 1. Prácticas económicas alternativas (PEA) en Zaragoza: entrevistas y cuestionarios realizados

\begin{tabular}{|c|c|c|c|c|}
\hline Tipo de PEA & Número & Participantes & Entrevistas & Cuestionarios \\
\hline Huerto urbano & 6 & 152 & 3 & 8 \\
\hline Mercado agroecológico & 1 & 30 & 1 & 0 \\
\hline $\begin{array}{c}\text { Cooperativa de consumo. } \\
\text { Grupo de consumo }\end{array}$ & 1 & 80 & 1 & 4 \\
\hline Red de trueque & 1 & 148 & 1 & 19 \\
\hline Banco de tiempo & 1 & 788 & 1 & 11 \\
\hline Moneda social & 1 & 0 & 1 & 0 \\
\hline Centro social autogestionado & 3 & 170 & 2 & 8 \\
\hline TOTAL & 27 & 1710 & 11 & 96 \\
\hline
\end{tabular}

Fuente: elaboración propia

Otra técnica cualitativa, aplicada en el caso de los centros sociales autogestionados, ha sido la observación participante. Dado el carácter asambleario de estos centros, los autores fueron invitados a asistir a la asamblea para exponer los objetivos y características de la investigación; 
ello permitió un conocimiento directo de su proceso de toma de decisiones y de algunos de sus temas de interés, así como participar posteriormente en algunas de sus actividades.

Como las entrevistas son una fuente de información representativa y fiable, dada la posición de las personas entrevistadas en las PEA, en ellas se ha basado prioritariamente el trabajo de investigación. Cuestionarios, observación participante y páginas web aportan información complementaria, a la vez que cumplen funciones de verificación, en el proceso comúnmente conocido como triangulación (Moro \& Lamarque, 2019).

\section{Resultados: las prácticas económicas alternativas en Zaragoza}

En este apartado se presentan los resultados de la investigación realizada: cómo funcionan las PEA identificadas en la ciudad, qué relación tienen con los movimientos sociales de base y con el gobierno local y cómo se integran en el espacio urbano.

\subsection{Las prácticas agroecológicas}

En Zaragoza, como muestra la Tabla 1, se han identificado los tres tipos de PEA agroecológicas seleccionadas en el apartado dedicado al marco teórico, que corresponden a las fases de producción, intercambio y consumo: seis huertos urbanos comunitarios, un mercado agroecológico y catorce grupos de consumo, de entre los que destaca una cooperativa de mayor tamaño.

Hay seis parcelas urbanas dedicadas a huertos comunitarios: dos de ellas se ubican en parques públicos -el de San José y el Oliver, desde 1994 y 2008, respectivamente- y cuatro en zonas libres dentro del espacio urbano: El Gancho (desde 2010), Parque Goya (2011), Hortal del Canal (2014) y Delicias (2019). Las parcelas cuyos responsables han podido ser entrevistados todos menos El Gancho y Hortal del Canal- albergan un total de 152 huertos (véase localización en Figura 1).

Todas las parcelas, excepto la de El Gancho, son de propiedad municipal. Las dos de los parques públicos - que se ubican en barrios obreros- están gestionadas directamente por el Ayuntamiento, que cede el uso de los huertos de forma gratuita a personas jubiladas o pensionistas, que se turnan cada tres años mediante sorteo. El cultivo tiene que ajustarse a patrones ecológicos y el Ayuntamiento facilita abono y herramientas.

La parcela de Parque Goya, donde hay 115 huertos, se ubica en un barrio periférico de clase media, de reciente construcción. El Ayuntamiento, dentro del programa municipal "Agros" para la recuperación de la huerta tradicional, convocó un concurso de licitación para la explotación 
del espacio en forma de huertos ecológicos. El concurso lo ganó una asociación sin ánimo de lucro que promueve, ente otras, actividades de ocio alternativo en la sociedad. Se cobra un alquiler a los usuarios de los huertos para hacer frente al pago del canon municipal y los gastos de funcionamiento de la parcela; el alquiler incluye el uso de herramientas, el trabajo de la tierra con una mula mecánica dos veces al año, el abonado con productos ecológicos dos veces al año y el agua. La asociación gestora se reserva algunos huertos para sus propios fines sociales.

El Hortal del Canal se ubica en otro barrio de clase media y reciente construcción. Forma parte también del programa "Agros" y responde al mismo modelo que Parque Goya en cuanto al régimen de concesión, que fue adjudicada igualmente a una asociación sin ánimo de lucro.

Figura 1. Localización de las prácticas económicas alternativas en Zaragoza

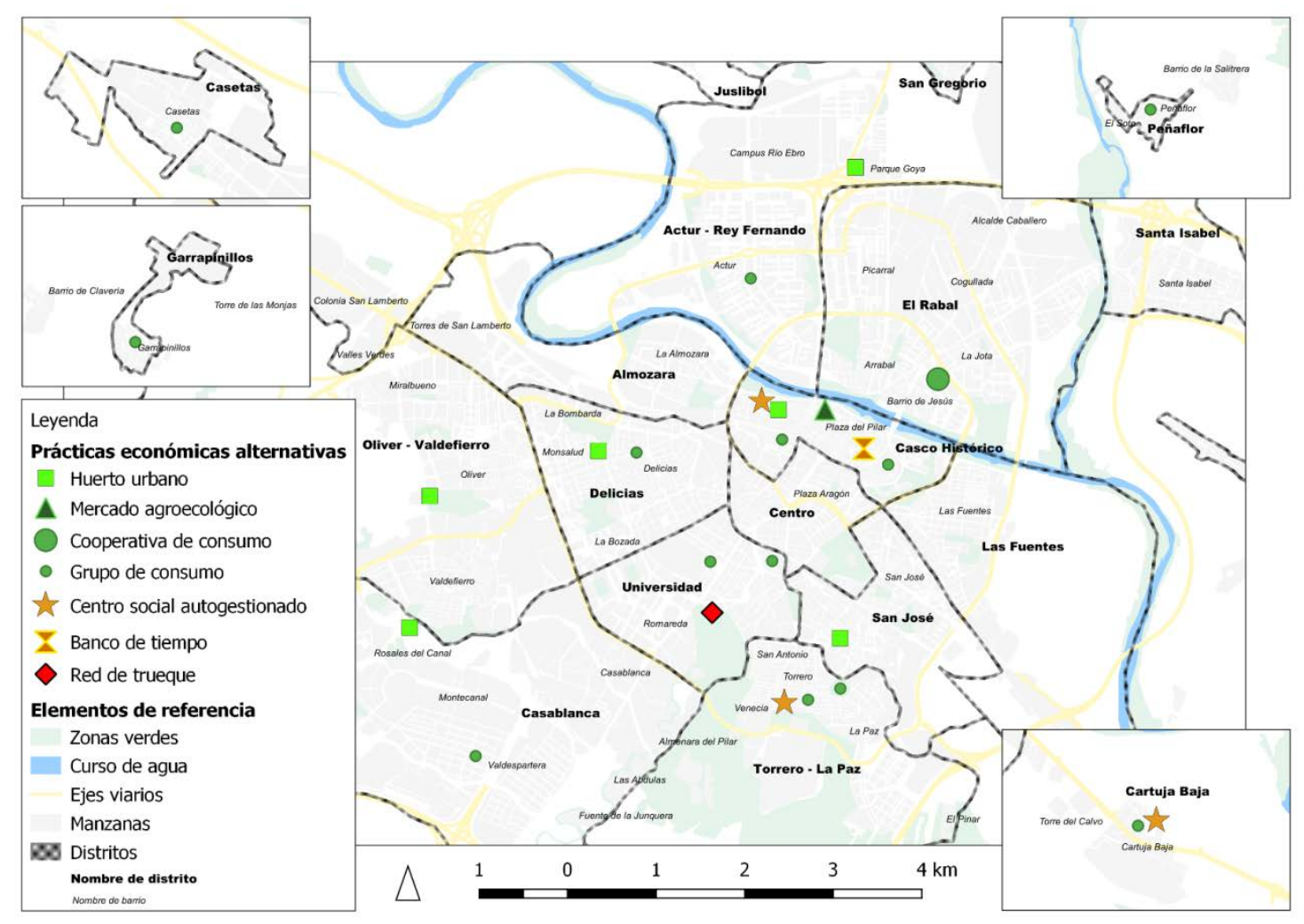

Fuente: elaboración propia

La iniciativa de los huertos de Delicias, que es un barrio obrero de la primera época de la industrialización de Zaragoza, partió de entidades sociales sin ánimo de lucro que trabajan en colaboración con las asociaciones vecinales. Presentaron un proyecto al Ayuntamiento, que lo asumió, aportando una parcela de su propiedad y cediendo la gestión al colectivo de entidades, que cubre los gastos mediante subvenciones municipales y recursos propios. Uno de los huertos se dedica a usos comunes, otros tres se reservan para los proyectos de las entidades 
promotoras, otros dos para proyectos de asociaciones y entidades del barrio y el resto son huertos compartidos, asignándose cada uno a tres personas de tres unidades familiares distintas.

Los huertos de El Gancho se ubican en el casco histórico de la ciudad, en una parcela privada con cuyo propietario el Ayuntamiento acordó una cesión temporal de uso, en el marco del programa municipal "Esto no es un solar", con el que se pretende que los solares sin perspectivas de edificación próxima queden disponibles para uso de los vecinos. En este caso se decidió acondicionarlo para huerto comunitario, cediéndose el uso y gestión a una entidad social sin ánimo de lucro.

Todos los huertos citados han de atenerse a dos reglas básicas: cultivarse mediante métodos ecológicos y dedicar sus productos al autoconsumo, en ningún caso a la venta.

El mercado agroecológico funciona todos los sábados del año, en horario de mañana, en el centro simbólico de la ciudad, la Plaza del Pilar (Figura 1). Su implantación en 2009 supuso la recuperación de los viejos mercados tradicionales. La iniciativa fue del Ayuntamiento, el Centro de Estudios Rurales y de Agricultura Internacional (CERAI), la Unión de Agricultores y Ganaderos de Aragón (UAGA) y el Comité de Agricultura Ecológica. Aprobada su normativa por el Ayuntamiento, UAGA y CERAI quedaron como gestores del mismo.

Los participantes pagan una tasa municipal por ocupación de suelo público y deben acreditar que son agricultores o artesanos con certificación ecológica o en fase de reconversión; adquieren el compromiso de vender exclusivamente productos propios. Acuden unos 30 productores. No se dispone de recuentos sistemáticos de compradores, pero los gestores estiman en unas dos mil personas las que acuden cada sábado.

Es un mercado de proximidad, por lo que se priorizan los productos procedentes de un radio de 120 kilómetros en torno a Zaragoza. Lo que se valora principalmente es la contribución al sostenimiento económico de los productores que han apostado por lo ecológico y la recuperación de las relaciones directas entre estos y los consumidores.

Se han localizado en diversos barrios de Zaragoza (Figura 1) trece pequeños grupos de consumo agroecológico, todos los cuales están integrados en una red virtual que cubre todo Aragón (Eco Red, fundada en 2011) a la que también están adscritos agricultores y artesanos. La red pretende crear vínculos entre consumidores y productores, con el objetivo de mejorar las relaciones mutuas y facilitar el consumo de productos ecológicos. Los grupos de consumo que 
la integran son de tamaño reducido. ${ }^{4}$ No están acogidos a ninguna figura legal, aunque alguno se ha inscrito como asociación. En ellos cada familia asume una función - llevar la contabilidad o encargarse de ciertos pedidos- y las tareas se reparten de forma consensuada; es normal que las transacciones monetarias se hagan directamente, en metálico, sin recurrir a los medios de pago que ofrecen las entidades financieras, como tarjetas de crédito o transferencias.

Además del compromiso ecológico, hay otros dos elementos destacables en estos grupos: primero, una actitud hacia los agricultores en la línea del comercio justo, como refleja en sus propias palabras la persona entrevistada:

Si yo compro borrajas a un productor, no se las voy a comprar a 40 céntimos, como me las venden en la verdulería, porque es indigno, porque hay explotación en ese precio fijo; si yo las compro a un euro sé que ese es el precio de la borraja en el campo, que ese es el precio digno para el agricultor; yo creo que ahí sí que no hay tejemanejes de ningún tipo, sino que hay una garantía de que estoy pagando lo justo por eso. ${ }^{5}$

Segundo, la asunción de un sistema de certificación ecológica extraoficial, al que denominan Sistema Participativo de Garantía, que la persona entrevistada define así:

Sistema de certificación alternativa al convencional, que consiste en que los propios productores y grupos de consumo son los que certifican, a través de la confianza, que el producto sea ecológico; el productor no tiene una certificación oficial, sino que se basa en la confianza de los consumidores ahorrándose así las cuotas de las certificaciones y ganando la confianza de la gente. ${ }^{6}$

La cooperativa de consumo "El Bisaltico" -que no está en Eco Red- se fundó en 2003, cuando los consumidores tenían serias dificultades para abastecerse de producto ecológico por la escasez de oferta y de puntos de venta. Llegó a tener 162 socios, pero ahora que la distribución comercial ha mejorado cuenta con 80; cuando alguien se inscribe tiene que aportar una cantidad inicial al fondo social. Dispone de tienda física (Figura 1) y la gestión diaria la lleva a

4 Los más grandes registrados en la ciudad agrupan a 20 familias; los más pequeños entre 5 y 7 (http://ecoredaragon.blogspot.com/p/grupos-de-consumo.html).

5 Entrevista a la persona responsable de Eco Red Aragón (27 de septiembre de 2017).

6 Entrevista a la persona responsable de Eco Red Aragón (27 de septiembre de 2017). En la página web de Eco Red hay una relación de productores acogidos a este sistema (http://ecoredaragon.blogspot.com/p/productores.html). 
cabo un gerente con contrato y sueldo. Funciona como central de compras y acepta solo productos con certificación ecológica oficial. Priorizan la compra directa y la proximidad, pero no aplican estos criterios de forma exclusiva, pues trabajan también con distribuidores y proveedores de otras regiones.

\subsection{Las monedas comunitarias}

Se han identificado en la ciudad ejemplos de los tres tipos de monedas comunitarias citadas en el apartado dedicado al marco teórico: la más antigua es el banco de tiempo, al que siguieron los mercadillos de trueque, organizados pronto en red, y finalmente la moneda social Ebro, de tipo LETS, que actualmente no está operativa.

El banco de tiempo se creó en 2007, a raíz de la firma de un convenio entre el Ayuntamiento y la Federación de Asociaciones de Barrio de Zaragoza, que es la entidad que lo gestiona. Su vinculación al movimiento vecinal le permitió comenzar con un número significativo de socios y funcionar desde el principio a escala de toda la ciudad. La gestión diaria la lleva una persona contratada por la Federación, aunque es el Ayuntamiento quien aporta el dinero. La oficina está en la sede asociativa, que ocupa un piso de propiedad municipal en el casco histórico, cedido gratuitamente (Figura 1).

Tiene cerca de 800 socios, que ofrecen un amplio abanico de servicios: ayuda en el hogar, reparaciones domésticas, clases, acompañamiento, mudanzas, actividades comunitarias y otras. A lo largo del año se producen más de 200 intercambios, cifra sensiblemente inferior a la de socios, lo cual revela el problema que comparte con la mayoría de los bancos de tiempo: la dificultad de equilibrar la oferta y la demanda de servicios; dada la amplia gama de los que se ofrecen se necesita un elevado número de socios que participen activamente para alcanzar un umbral significativo de economías de escala (Climent \& Lardiés, 2019a).

Cada servicio prestado se valora según el tiempo empleado, sin considerar ni su cualificación ni su cotización económica; la unidad de valor de los intercambios es el tiempo de trabajo, bajo la filosofía de que el tiempo de vida es igual de valioso para todo el mundo.

El objetivo principal del banco del tiempo, tal como afirma la persona entrevistada, no es económico, sino social: reforzar el sentimiento de vecindad, a la par que crear redes de autoayuda. Para favorecer la consecución de ese objetivo la persona encargada de la gestión organiza actividades complementarias (visitas culturales o talleres) para que los socios se encuentren y conozcan, propiciando el contacto directo que facilite los intercambios. En estas actividades participan cerca de 400 personas al año. 
El primer mercado de trueque de que se tiene constancia en la ciudad tuvo lugar el año 2009 en Peñaflor de Gállego, una entidad de población (o barrio rural) del municipio de Zaragoza. Es el de trayectoria más larga, pues se ha desarrollado una vez al año ininterrumpidamente hasta 2018. Fue iniciativa de uno de los grupos de consumo incluidos en Eco Red.

En 2011 dicho grupo, el Banco de Tiempo de Zaragoza y una fundación ligada a una asociación vecinal decidieron crear la Red de Trueque de Zaragoza, para impulsar, organizar y coordinar mercados de trueque en la ciudad. Desde entonces mantienen un blog que da información puntual sobre dichos eventos, a la vez que asesoran y orientan a quienes quieren montar alguno. Desde 2014 organizan una feria de trueque de toda la ciudad en el parque principal, coincidiendo con las fiestas patronales (Figura 1).

Los mercados de trueque se desarrollan mediante eventos efímeros, igual que el mercado agroecológico, pero a diferencia de este no disponen de un sitio estable ni de una periodicidad fija: la Tabla 2 recoge los celebrados desde 2012. Se observa que las mayores frecuencias coinciden con los años de la crisis.

Tabla 2. Mercados de trueque en Zaragoza (2012-2019)

\begin{tabular}{|c|c|c|c|c|c|c|}
\hline \multirow{2}{*}{ AÑO } & \multirow{2}{*}{ NÚMERO } & \multicolumn{5}{|c|}{ ENTIDAD ORGANIZADORA } \\
\cline { 3 - 7 } & & $\begin{array}{c}\text { Asociación } \\
\text { de vecinos }\end{array}$ & $\begin{array}{c}\text { Otra } \\
\text { asociación }\end{array}$ & $\begin{array}{c}\text { Otra } \\
\text { PEA }\end{array}$ & $\begin{array}{c}\text { Entidad } \\
\text { privada }\end{array}$ & Universidad \\
\hline 2012 & 13 & 7 & - & 5 & 1 & - \\
\hline 2013 & 10 & 2 & 2 & 3 & 2 & 1 \\
\hline 2014 & 15 & 5 & 1 & 5 & 1 & 3 \\
\hline 2015 & 3 & 1 & - & 2 & - & - \\
\hline 2016 & 4 & - & 1 & 3 & - & 2 \\
\hline 2017 & 7 & - & 1 & 4 & - & 1 \\
\hline 2018 & 6 & 1 & - & 2 & 2 & 7 \\
\hline 2019 & 4 & 1 & 1 & 1 & 1 & 7 \\
\hline Total & 62 & 17 & 6 & 25 & 7 & - \\
\hline
\end{tabular}

Fuente: elaboración propia a partir de los Mercados de trueque en Zaragoza 
Otra diferencia respecto al mercado agroecológico es que de este se encarga siempre el mismo gestor, mientras que los de trueque son organizados por diversas entidades: destacan en primer lugar las que desarrollan otras PEA, con el 40\% del total de eventos. Siguen las asociaciones de vecinos, con el 28\%, algunos centros universitarios, otras asociaciones y algunas entidades privadas. Los lugares de desarrollo cambian en función del organizador, coincidiendo con su sede o con algún espacio público cedido.

No es posible saber el número de participantes en estos mercados. La persona entrevistada, responsable de la feria de trueque, que es el evento más concurrido, estimó en unas 300 personas las que participaron en la última edición de la misma.

En los mercados de trueque está prohibido el uso de dinero: los intercambios han de ser de bienes por bienes. El valor viene fijado por la utilidad real que reportan a quienes quieren intercambiarlos: si un objeto ha dejado de ser útil a su propietario puede cambiarlo por otro, en vez de tirarlo, con lo que se avanza hacia un consumo más responsable, como sugieren los lemas de la feria de trueque: "Reducir, reutilizar, reciclar. Buscando dar una segunda vida a los objetos. Cambiar cosas para cambiar las cosas". A diferencia de los bancos de tiempo, en los mercados de trueque los intercambios son bilaterales, aunque se permite llegar a acuerdos entre tres o más personas.

Un colectivo ligado al movimiento 15M de Zaragoza creó la moneda social Ebro en 2012. Desde el principio se integró en la plataforma digital Community Exchange System (CES), lo que garantizó su convertibilidad con todas las monedas sociales incluidas en esta red global. ${ }^{7}$ Quien quisiera formar parte del grupo de intercambio debía inscribirse previamente en la plataforma y allí podía anunciar sus ofertas de bienes o servicios y ver las ofertas de los demás que pudieran convenirle.

Para materializar intercambios se celebraban periódicamente mercados, con los que se pretendía difundir la existencia de la moneda social entre un público más amplio y así hacer crecer la comunidad. Al principio se realizó un mercado al mes, espaciándose progresivamente a uno cada dos, tres y seis meses, hasta que se suspendieron en 2015. Las causas de esta suspensión fueron el cansancio producido por el excesivo trabajo voluntario que asumía un número reducido de personas y la dificultad de casar oferta y demanda, de modo similar a como se ha explicado respecto al banco de tiempo. A la suspensión de los mercados periódicos

7 Es una plataforma en línea que presta servicio a 1091 grupos de intercambio en 102 países https://www.community-exchange.org/home/ 
le siguió poco después el cese de actividad. La moneda social Ebro actualmente no está operativa, aunque sigue inscrita en el CES, en situación de stand by, según expresión de la persona entrevistada.

\subsection{Los centros sociales autogestionados}

El primer intento de creación de un centro social autogestionado (CSA) en Zaragoza se produjo en 1986, cuando un grupo anarquista ocupó un local abandonado, que fue desalojado al cabo de trece días. A él siguieron otros de mayor pervivencia y repercusión social, cerrándose un primer ciclo en 2001, con el abandono del CSA Miju tras dos años de funcionamiento (Dieste \& Pueyo, 2003).

Actualmente hay tres en activo. El más antiguo es el Centro Social Okupado Kike Mur, creado en el año 2010 tras la ocupación de un edificio de la antigua prisión provincial, en el barrio obrero de Torrero (Figura 1). Cuando se construyó el nuevo centro penitenciario, en un municipio del área periurbana de Zaragoza, la mayor parte de las dependencias de la vieja cárcel fueron demolidas, construyéndose en su lugar unos bloques de viviendas sociales, pero se conservó el edificio central. Dicho espacio debería haber albergado un centro cívico, pero el Ayuntamiento - a quien se cedió el inmueble- nunca llegó a tener un proyecto claro. Tras años de abandono fue ocupado por un colectivo de inspiración libertaria, que lo mantiene activo desde entonces.

En 2013 se creó el Centro Social Comunitario Luis Buñuel, también mediante ocupación de un edificio público, una construcción de finales del siglo XIX -ubicada en el barrio medieval de San Pablo (Figura 1)- que tuvo diferentes usos a lo largo de su historia, siendo instituto de educación secundaria el último de ellos; dada la inadecuación de las instalaciones para esta función se construyó un centro nuevo en un barrio vecino y el edificio quedó vacío en 2005, sin que su propietario, el Ayuntamiento, previera ningún uso concreto, hasta que un colectivo del movimiento $15 \mathrm{M}$ lo ocupó, manteniéndose así desde entonces.

El tercero, fundado también en 2013, es el Centro Social Autogestionado La Cartuja, ubicado en la entidad de población (o barrio rural) del mismo nombre (Figura 1). Es una iniciativa mucho más modesta, que utiliza el local de una peña, que lo cede sin contrapartida económica.

Estos centros se rigen por una asamblea semanal, en la que se toman las decisiones relativas a la gestión interna y se aprueban las actividades a realizar. Entre estas se incluyen muchas de carácter cultural, como conciertos, conferencias, espectáculos, talleres de arte, de bricolaje o yoga. Pero son especialmente importantes - afirman las personas entrevistadas- las de carácter social, como las que organizan colectivos feministas y antifascistas, plataformas como las de 
afectados por la hipoteca o de apoyo a refugiados y a colectivos laborales. La participación en las actividades está abierta a todo el mundo y es gratuita. El Luis Buñuel dispone de un servicio de asesoría social y además ha llevado a cabo diversos proyectos comunitarios centrados en el barrio.

Los dos centros ocupados disponen de una tienda gratuita: cualquiera puede donar lo que ya no necesita y llevarse lo que precise. Además organizan periódicamente mercadillos de trueque. El Luis Buñuel tiene un huerto comunitario en su patio. Este y el CSA La Cartuja son la sede de sendos grupos de consumo agroecológico. La moneda social Ebro tuvo su sede y celebró la mayor parte de sus mercados en el Luis Buñuel.

Los CSA, por tanto, desarrollan actividades variadas, preferentemente centradas en los servicios socio-culturales, y además son sede y punto de apoyo de otras PEA.

\subsection{Los participantes en las prácticas económicas alternativas}

Los cuestionarios cumplimentados ofrecen información relevante sobre el perfil sociodemográfico de las personas que participan en las PEA afincadas en Zaragoza. Cabe señalar, para empezar, que existe un significativo desequilibrio de género: el $42 \%$ son hombres y el $58 \%$ mujeres.

En la Tabla 3 se recogen otras características sociodemográficas, que permiten definir el perfil de los participantes en las PEA: predominan los adultos de entre 35 y 50 años (45\% del total), las personas con educación universitaria (58\%), los trabajadores en activo (69\%), quienes viven en hogares de dos personas (36\%) y quienes disponen de un nivel de ingresos de entre 20 y 40 mil euros anuales (32\%). Predominan, por tanto, los adultos de edad madura, viviendo en pareja, con un nivel de formación alto e ingresos medio-altos.

Para captar su orientación ideológica, atendiendo a los tres posicionamientos sobre qué es lo alternativo a que se ha hecho referencia en la introducción, se les planteó la siguiente pregunta: "Indique con cuál de estas posturas se siente más identificado: 1) rechazo totalmente el capitalismo como sistema económico y social; 2) intento corregir los aspectos más injustos del capitalismo actual; 3) trabajo por construir unas relaciones económicas que me permitan vivir al margen del capitalismo". 
Tabla 3. Partícipes en Prácticas Económicas Alternativas: características sociodemográficas

\begin{tabular}{|c|c|c|c|c|c|}
\hline GRUPO & EDAD & EDUCACIÓN & OCUPACIÓN & $\begin{array}{c}\text { PERSONAS } \\
\text { POR HOGAR }\end{array}$ & INGRESOS \\
\hline A & 8 & 7 & 15 & 20 & 14 \\
\hline B & 43 & 16 & 9 & 34 & 28 \\
\hline C & 27 & 14 & 2 & 10 & 30 \\
\hline D & 14 & 55 & 66 & 25 & 9 \\
\hline No contesta & 3 & 3 & 3 & 6 & 14 \\
\hline Total & 95 & 95 & 95 & 95 & 95 \\
\hline
\end{tabular}

\begin{tabular}{|c|c|c|c|c|c|}
\hline \multicolumn{7}{|c|}{ Valores de las variables en cada grupo } \\
\hline GRUPO & EDAD & EDUCACIÓN & OCUPACIÓN & $\begin{array}{c}\text { PERSONAS } \\
\text { POR HOGAR }\end{array}$ & $\begin{array}{c}\text { INGRESOS } \\
\text { (miles de } \\
€ \text { ) }\end{array}$ \\
\hline A & $<35$ & Primaria & Jubilado & 1 & $<10$ \\
\hline B & $35-50$ & Bachillerato & Desempleado & 2 & $10-20$ \\
\hline C & $51-65$ & FP & Estudiante & 3 & $20-40$ \\
\hline D & $>65$ & Universidad & Activo & $>3$ & $40-60$ \\
\hline
\end{tabular}

Fuente: elaboración propia

La respuesta más frecuente fue la segunda, con el 57\% del total; le sigue la primera, con el 24\% y la tercera, con el 19\%. Vale la pena señalar que de esta tónica general se apartan los CSA, donde la postura de rechazo es absolutamente mayoritaria, si bien hay que tomarlo con mucha prevención dado el escaso número de participantes en los CSA que cumplimentaron el cuestionario. De lo anterior se desprende que la mayor parte de quienes participan en el conjunto de PEA seleccionadas en Zaragoza no pretenden acabar con el sistema, sino corregir sus aspectos más injustos. Los anticapitalistas, es decir, quienes rechazan de plano el sistema, son casi la cuarta parte del total y quienes pretenden vivir al margen del mismo, se acercan a la quinta parte.

Otro rasgo destacable es que el $48 \%$ de las personas que han cumplimentado el cuestionario afirma que participa en una sola PEA, frente al 52\% que lo hace en más de una. De estas últimas, una quinta parte participa solo en monedas comunitarias -por ejemplo, en el banco de 
tiempo y los mercados de trueque- pero en los demás casos combinan alguna de estas con alguna de las prácticas agroecológicas o con los centros sociales autogestionados. La participación doble o múltiple muestra un compromiso personal con los valores de solidaridad social y sostenibilidad ambiental.

A modo de recapitulación, puede afirmarse que los participantes en las PEA no son en su mayor parte ni revolucionarios ni marginales, sino personas que pretenden vivir en la sociedad actual mejorándola desde dentro. Tienen una formación elevada y un buen nivel de ingresos y muestran un alto grado de compromiso personal.

\subsection{Las prácticas económicas alternativas en el espacio y las políticas urbanas}

Las PEA analizadas se localizan de forma dispersa por el espacio urbano, tanto en la ciudad compacta como en las otras entidades de población, que en Zaragoza se denominan barrios rurales (Figura 1). El mercado agroecológico y el banco de tiempo se ubican en el casco histórico. Los mercadillos de trueque, por ser eventos efímeros y esporádicos, sin periodicidad fija, no se han cartografiado, aunque sí la feria de trueque, que se celebra una vez al año en el Parque Grande, situado al final del eje principal del ensanche burgués.

Los grupos de consumo se localizan por toda la ciudad: dos en el casco histórico, otros dos en el ensanche burgués (Universidad), cuatro en barrios obreros de la primera industrialización (Barrio de Jesús, Delicias y Torrero), otros dos en barrios recientes de clase media (Actur y Valdespartera) y cuatro más en los barrios rurales (Casetas, Garrapinillos, Peñaflor y Cartuja Baja).

Los huertos comunitarios tienen una localización periférica: tres se sitúan en los límites del continuo urbano, en barrios de reciente construcción (Oliver, Parque Goya y Rosales del Canal), dos en la periferia de barrios obreros de la primera industrialización (San José y Delicias) y uno en el casco histórico.

Los centros sociales autogestionados se ubican en tres tipos de emplazamiento: el casco histórico, un barrio obrero de la primera industrialización (Torrero) y un barrio rural (La Cartuja Baja).

Una de las preguntas del cuestionario a los participantes en las PEA se refería al domicilio, expresado en términos de barrio. Las 85 respuestas obtenidas se distribuyen de la siguiente manera: 12 viven en el casco histórico, 9 en el ensanche burgués, 32 en barrios obreros de la primera industrialización, 26 en barrios recientes de clase media y 6 en barrios rurales. Por 
tanto, las personas que participan en las PEA se distribuyen también de forma dispersa por toda la ciudad.

El Ayuntamiento de Zaragoza ha apoyado a muchas de las PEA aquí descritas. 8 Donde más claramente se aprecia la apuesta municipal por ellas es en las de carácter agroecológico: el mercado agroecológico está incluido en la red de mercados municipales; los huertos urbanos comunitarios se desarrollan en terrenos de propiedad municipal, cuya gestión lleva el propio ayuntamiento o cede a otras entidades, en el marco del programa municipal Agros; el huerto de El Gancho se sale de este esquema, pues está en una parcela privada, pero funciona también dentro de un programa municipal, "Esto no es un solar". Por el contrario, no hay apoyo municipal a los grupos de consumo, porque se trata de iniciativas particulares e informales cuyos promotores no lo solicitan.

Respecto a las monedas comunitarias, el Ayuntamiento fue impulsor del banco de tiempo y lo apoya financieramente desde el mismo momento de su creación, aunque delega su gestión en la federación de asociaciones de vecinos. Por el contrario, no hay apoyo municipal a los mercados de trueque, porque se trata de iniciativas particulares e informales cuyos promotores no lo solicitan; no obstante, apoya la feria de trueque anual mediante la cesión de uso de espacio público y su inclusión en el programa de las fiestas patronales. No solicitaron apoyo los promotores de la moneda social.

La actitud del Ayuntamiento hacia los CSA que ocupan edificios municipales es, como mínimo, de tolerancia: siendo propietario de los mismos, no ha tomado ninguna iniciativa de desalojo, mantiene el suministro de agua y se hace cargo de los gastos de electricidad. Esta actitud revela un cierto reconocimiento a la labor sociocultural que realizan, de forma totalmente altruista y voluntaria, sin coste para el erario público. En marzo de 2018, gobernando Zaragoza en Común, se intentó ir más allá, mediante la firma de un convenio de colaboración con el Luis Buñuel, para regularizar la ocupación: los ocupantes se constituyeron en asociación, presentaron un proyecto de actividades y el ayuntamiento les cedió el uso del edificio para su desarrollo. Dicho convenio fue recurrido judicialmente por otra asociación - con el apoyo del Partido Popular- y el Tribunal Superior de Justicia de Aragón lo declaró nulo en noviembre de 2019. El Ayuntamiento actual, gobernado por Partido Popular y Ciudadanos, no ha tomado ninguna

8 La ciudad ha tenido alcaldes del Partido Socialista Obrero Español durante 28 años (1979-1995 y 2003-2015) y del Partido Popular en 8 (1995-2003). En 2015-2019 gobernó en minoría Zaragoza en Común, coalición electoral ligada a Podemos. Desde las elecciones de 2019 lo hace una coalición del Partido Popular y Ciudadanos. 
decisión tras la sentencia, por lo que se mantiene la situación de ocupación en las mismas condiciones que antes.

\section{Discusión}

Los resultados del análisis realizado arrojan luz sobre el funcionamiento de las PEA, sus limitaciones como alternativa al sistema y su relación con los movimientos sociales de base, así como sobre el papel de la administración local. También permiten conocer y valorar su integración en el espacio urbano.

\subsection{Las prácticas agroecológicas: hacia una producción y consumo sostenibles}

El principal rasgo que salta a la vista respecto a las prácticas agroecológicas en Zaragoza es su falta de integración: los huertos comunitarios, el mercado agroecológico y los grupos de consumo cubren las tres fases del circuito económico, pero no están conectados entre sí, operando cada uno al margen de los demás.

Los huertos funcionan en régimen de autoconsumo, lo cual viene forzado por la normativa que rige la producción alimentaria, pero además es coherente con la finalidad última de los mismos, que no es económica, sino social: las entidades gestoras de los huertos no tienen como objetivo la obtención de ingresos, sino crear ámbitos de socialización para colectivos menos favorecidos (jubilados o jóvenes con problemas), reforzar los lazos internos de las comunidades de los barrios en que se asientan y hacer visibles a los habitantes de entornos urbanos la íntima vinculación de la sociedad con la naturaleza, plasmada claramente en el cultivo de la tierra para la obtención de alimento. Esta es la tónica general, como ponen de manifiesto otros trabajos: Gómez (2019) les atribuye una función social -favorecer relaciones entre familias del mismo barrio- y otra didáctico-ambiental; Larrubia et al. (2020), estudiando el caso de Málaga, indican que los huertos urbanos contribuyen al fortalecimiento de redes sociales y a la protección medioambiental, merced al empleo de métodos ecológicos.

El mercado agroecológico reúne a productores profesionales -agricultores y artesanos- y consumidores, que realizan operaciones de compra-venta en un espacio y tiempo previamente fijados, con una periodicidad establecida. De todas las prácticas aquí estudiadas es la que más se asemeja a las convencionales, en tanto que los vendedores persiguen la obtención de beneficios económicos. No obstante, como afirman sus gestores, su objetivo principal no es crematístico, sino demostrativo: se trata de que la población urbana conozca a productores del entorno rural que cultivan la tierra de manera respetuosa con los procesos naturales y consuma 
sus productos, los cuales reúnen una serie de cualidades alimenticias y simbólicas - sanos y naturales- diferentes de las de los alimentos convencionales; se presupone que ese efecto demostración ayudará a consolidar la producción agroecológica. En la misma línea se manifiestan los gestores de los mercados de otras ciudades, en cuya opinión estos ofrecen beneficios económicos, pero también de otro tipo: transformación de hábitos alimentarios, promoción de la economía social y desarrollo de procesos de producción y consumo más responsables con el medio ambiente (Méndez \& Monteserín, 2017).

Pese a sus aspectos positivos el mercado agroecológico de Zaragoza presenta una limitación importante: tratándose de una ciudad grande, un solo mercado ubicado en el centro resulta de difícil acceso para los habitantes de los barrios; hacer un viaje en transporte público cargando con las bolsas de la compra no es una experiencia cómoda y el uso del transporte privado queda descartado por las restricciones de aparcamiento. Lo ideal sería avanzar hacia un modelo de mayor dispersión, con varios mercados funcionando en la ciudad, establecidos de acuerdo con las asociaciones de vecinos y los pequeños comerciantes de los barrios. Pero esta posibilidad se enfrenta a una limitación difícil de superar: la falta de oferta, tanto por el número de agricultores que podrían participar en ellos, como por el modesto tamaño de sus explotaciones agrarias. Esta limitación se da también en Madrid, donde hay varios mercados, pero las distancias a recorrer por los consumidores son muy altas, dado el gran tamaño de la ciudad (Méndez \& Monteserín, 2017).

El Ayuntamiento de Zaragoza apoya la iniciativa, a diferencia de lo que ocurre en otras ciudades. Por ejemplo, en Alicante el mercado agroecológico está gestionado por grupos de activistas por la soberanía alimentaria, tanto productores como consumidores, que no quisieron aceptar lo que juzgaron como imposiciones de la autoridad municipal (Espinosa et al., 2020); en él además no se exige una certificación ecológica oficial, asumiendo los sistemas participativos de garantía a que se ha hecho referencia en el caso de los grupos de consumo. Por todo ello el mercado alicantino presenta un carácter más alternativo que el de Zaragoza, en el sentido de que sus prácticas están más alejadas de las convencionales. Por otra parte, el mercado de Alicante se celebra en un huerto comunitario ocupado, lo que abre la puerta a una cierta cooperación entre ambos tipos de prácticas, a diferencia de lo observado en Zaragoza.

La existencia de pocos mercados en las ciudades y su falta de integración con otras prácticas agroecológicas muestran que queda un largo camino por recorrer "hasta convertirlos en un verdadero modelo de consumo alternativo que vaya más allá de iniciativas valiosas pero 
puntuales" (Méndez \& Monteserín, 2017, p. 214). Para esto sería necesaria la implicación del sector púbico, singularmente de los ayuntamientos; pero estos tienen actitudes muy diferentes, como se ha visto en los casos de Zaragoza y Alicante. Por otra parte, un obstáculo difícil de superar es el requisito de la venta directa: con él se cumple el objetivo de facilitar una relación sin intermediarios entre productores y consumidores, pero obliga a aquellos a desplazarse y llevar a cabo tareas distintas de las específicas de su profesión. Una organización de tipo cooperativo entre productores podría facilitar la realización de estas tareas sin traicionar el espíritu de la venta directa.

Los grupos de consumo agroecológico de Zaragoza funcionan al margen de los huertos comunitarios, de los que no pueden proveerse, y del mercado agroecológico, al que no recurren. ${ }^{9}$ Estos grupos son "experiencias de colaboración entre consumidores urbanos organizados y productores agroecológicos de las áreas rurales o periurbanas próximas que permitan superar la actual hegemonía de la gran distribución" (Michelini et al., 2017, p. 682), mediante una relación comercial directa, sin intermediarios, que potencia la agricultura de proximidad o kilómetro 0 , como también se la denomina; en esto hay una clara coincidencia con el mercado agroecológico.

Un rasgo definitorio de los grupos de consumo de Zaragoza, compartido con los de otras ciudades, es que no exigen a sus proveedores una certificación ecológica oficial. Con ello buscan beneficiar a los agricultores, para quienes la obtención de dichas certificaciones implica unos gastos importantes, y a la vez manifiestan su rechazo a los mecanismos burocráticos del sistema. En su lugar han establecido un sistema participativo de garantía, basado en la confianza mutua, que refuerza los lazos entre productores y consumidores. Esto, unido al compromiso de compra a largo plazo, supone un apoyo importante a los agricultores, en la línea de la Community Supported Agriculture de Estados Unidos, cuyo ejemplo más relevante en España es la asociación "Bajo el Asfalto está la Huerta" de Madrid (López, 2015).

A pesar de la falta de integración económica entre ellas y los problemas que se han expuesto, las tres prácticas agroecológicas estudiadas en Zaragoza funcionan bien y exhiben una notable vitalidad. Pero distan mucho de constituir un "sistema alimentario local alternativo", en palabras de Michelini et al. (2017). Para avanzar en esa dirección sería necesaria una mayor integración,

9 Los socios de los grupos de consumo pueden acudir al mercado agroecológico a título individual, como cualquier otro ciudadano, pero no suelen hacerlo, puesto que su grupo les garantiza el aprovisionamiento de los productos que requieren. 
lo cual exigiría, por una parte, que los huertos comunitarios cambiaran de enfoque -algo sin sentido, dados los principios de sus entidades gestoras- o que surgieran nuevos huertos gestionados por agricultores profesionales, capaces de cumplir plenamente con la normativa alimentaria; algo de esto se está intentando en la ciudad por parte del Ayuntamiento, como se verá más adelante. Por otra parte, sería necesario reforzar la conexión entre producción y consumo; una vía para ello podría ser cambiar el enfoque de los grupos de consumo, incrementando su tamaño y profesionalizando la gestión, pero esta opción, que supondría una "neo-convencionalización, es decir, la adopción de formas de organización y gestión semejantes a las que practica la distribución alimentaria hegemónica" (Sánchez \& Espinosa, 2020, pp. 2425), es rechazada de plano por numerosos grupos de consumo, que se identifican plena y radicalmente con el modelo actual. No obstante, esta es la línea que ha adoptado en Zaragoza la cooperativa de consumo El Bisaltico, que fue pionera en el consumo agroecológico de la ciudad, pero se viene enfrentando crecientemente a la competencia de la distribución convencional -tanto de las tiendas especializadas como de las grandes superficies comercialeslo cual ha dado lugar a una reducción paulatina del número de socios; esta experiencia muestra que la neoconvencionalización no es una vía fácil de llevar a la práctica con éxito por parte de las cooperativas y grupos de consumo.

Para finalizar esta discusión sobre las prácticas agroecológicas, conviene no perder de vista que están en la línea de los objetivos de Desarrollo Sostenible de la ONU, entre los que se incluyen la búsqueda de la seguridad alimentaria y la agricultura sostenible.

\subsection{Las monedas comunitarias: el problema de la masa crítica}

Frente a la vitalidad de las prácticas agroecológicas, las monedas comunitarias se vienen enfrentando en Zaragoza a serios problemas de funcionamiento, cuya manifestación más grave fue la suspensión de la moneda social Ebro, que en la actualidad no está operativa; los mercados de trueque tuvieron su mayor desarrollo en los años de la crisis, pero desde 2015 su número ha disminuido notablemente; el banco de tiempo funciona por debajo de sus posibilidades, como indica el hecho de que el número de socios casi cuadriplica la cifra anual de intercambios.

El problema nuclear de estas PEA es la dificultad de equilibrar oferta y demanda; no es exclusivo de Zaragoza, pues son numerosas las redes de colaboración de este tipo que no alcanzan un tamaño suficiente para su viabilidad (Méndez, 2015). En efecto, si los asistentes a un mercado de trueque son pocos y llevan pocos objetos para trocar, es difícil que coincidan en el mismo 
espacio y tiempo un elevado número de personas con ofertas y demandas complementarias. El banco de tiempo y la moneda social permiten mayor flexibilidad, porque los intercambios son multilaterales y no sincrónicos, pero aun así es frecuente que algunos usuarios tengan ofertas atractivas, con las que acreditan tiempo o moneda, y no puedan gastar porque no hay usuarios que ofrezcan lo que ellos demandan; del mismo modo, algunos usuarios acumulan excesivamente en su debe; los gestores están atentos a evitar estos desequilibrios, pero, si el número de participantes es pequeño, el único medio para conseguirlo es restringir los intercambios, es decir, no aceptar demandas de quienes deben demasiado ni ofertas de quienes tienen una posición acreedora excesiva, con lo que se genera un círculo vicioso. Este problema es general: según un trabajo sobre los bancos de tiempo de varias ciudades españolas "los gestores [...] señalan claramente que la principal dificultad es la ausencia de una masa crítica para encajar oferta y demanda" (Climent \& Lardiés, 2019a, p. 139).

Otra de las razones de ese desequilibrio es que muchos participantes tienen una buena disposición a ofrecer servicios, pero son reacios a demandarlos, como afirma la persona responsable del banco de tiempo de Zaragoza. Autores como Markkanen \& Burgess (2015) constatan esta misma actitud, a la que se refieren como el obstáculo psicológico que impide pedir ayuda, lo cual tiene que ver con el hecho de que muchos participantes en bancos de tiempo asocian estos con tareas de voluntariado (Climent \& Lardiés, 2019b); el voluntario es una persona que ayuda, sin pedir nada a cambio, pero esa actitud no encaja con las monedas comunitarias, que se basan en la reciprocidad.

No obstante, algunos bancos de tiempo muestran un importante dinamismo, como el de Baracaldo, que ha alcanzado "una dimensión que supera nuestras más optimistas previsiones" (Pariza et al., 2014, p. 46) o el de Gorbals, en la ciudad de Glasgow, que ha desempeñado un papel destacado en el alivio de la pobreza y la exclusión social en un barrio especialmente vulnerable (Seyfang, 2004).

González et al (2019), en un estudio comparado sobre varias monedas sociales en España, constatan el debilitamiento de gran parte de ellas, remarcando así los problemas a que se enfrentan estas prácticas. Una de las reflexiones que apuntan dichos autores es que la recuperación parcial de la crisis económica ha podido influir en el desinterés por mantenerlas.

Las personas responsables de las monedas comunitarias actualmente existentes en Zaragoza -banco de tiempo y mercado de trueque- insisten en que estas prácticas no tienen una finalidad económica, sino social: fortalecer los vínculos entre las personas que integran la 
comunidad. Coinciden en ello con las apreciaciones de numerosos autores, que consideran que la función esencial de las monedas comunitarias es la de construir capital social (Collom, 2008; Valor \& Papaoikonomou, 2016). Para desarrollar esa función disponen de un punto fuerte: la red de trueque y el banco de tiempo de Zaragoza están integrados y coordinados entre sí, a diferencia de las prácticas agroecológicas.

\subsection{Prácticas económicas alternativas, activismo y movimientos sociales}

La población de Zaragoza es de 674997 habitantes; ${ }^{10}$ los 1710 participantes en las PEA analizadas (Tabla 1) son una minoría, aunque la estimación sea muy conservadora, como se explicó en el apartado metodológico. Esto, unido a los problemas de funcionamiento señalados, lleva a pensar que estas PEA tienen una capacidad de cambio o transformación social muy limitada. No obstante, debe recordarse que sus practicantes no son un grupo marginal aislado en un gueto, sino una población con un perfil sociodemográfico plural, en el que predominan los niveles altos de estudios y medio-altos de ingresos, que vive y desarrolla sus prácticas a lo largo y ancho de la ciudad. Su posicionamiento ideológico es crítico frente al capitalismo y su actitud personal de compromiso social está fuera de duda. Por todo ello su influencia en la ciudad puede ser mayor de lo que las cifras sugieren. Ni por su número ni por su posicionamiento político están en condiciones de producir un cambio radical en el modelo económico actual, pero pueden tener una influencia significativa orientando la sociedad hacia posiciones más ecológicamente sostenibles y socialmente solidarias.

Estas PEA mantienen una estrecha vinculación con los movimientos sociales urbanos de base. En algunos casos se trata de movimientos con décadas de historia y fuerte arraigo e influencia, formalizados y articulados institucionalmente. Destaca en primer lugar el movimiento vecinal, muy activo en la ciudad: las asociaciones de vecinos son impulsoras directas del banco de tiempo y la red de trueque, cuya gestión asumen; colaboran también en la gestión de algunos huertos urbanos y animan otras prácticas. ${ }^{11}$

Diversos movimientos de voluntariado, también de larga vida, organizados en fundaciones y organizaciones no gubernamentales, han puesto en marcha algunas PEA, como los huertos urbanos comunitarios. Organizaciones ecologistas fueron las que impulsaron la creación del

10 Instituto Nacional de Estadística: Cifras oficiales de población resultantes de la revisión del Padrón municipal a 1 de enero de 2019.

11 La persona responsable de la cooperativa de consumo agroecológico El Bisaltico explicó en la entrevista que las asociaciones de vecinos habían animado y apoyado la creación de la cooperativa. 
mercado agroecológico, que actualmente gestionan, y las que inspiraron la creación de los grupos de consumo agroecológico, aunque estos funcionan sin una organización formal.

Los centros sociales autogestionados son, de todas las descritas, las prácticas que mejor encarnan el espíritu activista y alternativo. Despliegan en los barrios una intensa actividad de servicios culturales y sociales, que trasciende al conjunto de la ciudad. Juegan además un papel importante como animadores y anfitriones de todos los demás tipos de PEA.

Los dos más grandes de la ciudad se identifican con el movimiento okupa, también con décadas de existencia. Este movimiento despierta recelos en buena parte de la población, que lo asocia con la ocupación de viviendas de propiedad privada. Pero los CSA se ubican en edificios vacíos de titularidad pública, por lo que no hay perjuicio a particulares; más bien al contrario, la ocupación les da nueva vida y los ocupantes los cuidan, llevando a cabo las tareas de mantenimiento necesarias. Estos centros funcionan de manera informal; no obstante, el Luis Buñuel se inscribió como asociación para negociar con el Ayuntamiento. Por el contrario, el Kike Mur, de inspiración libertaria, no se ha planteado en ningún momento su formalización. Esta diferencia entre centros que buscan una cierta institucionalización y otros que la rechazan abiertamente es común a otras ciudades (González et al., 2018).

A escala mundial las prácticas analizadas en este trabajo se originaron a raíz de la crisis de los setenta del siglo pasado. Las identificadas en Zaragoza son más recientes: las primeras fueron el huerto comunitario del Parque de la Memoria (1994), la cooperativa de consumo (2003) y el banco de tiempo (2007). Las restantes se crearon a partir de 2008, en el contexto de la última crisis, que fue factor impulsor: los productores agroecológicos, cuyos productos son más caros que los convencionales, trataron de buscar nuevos mercados, lo cual favoreció la venta directa a grupos de consumo, como iniciativa informal, y la puesta en marcha del mercado agroecológico en 2009, como iniciativa formal. El incremento de la pobreza y otros problemas sociales multiplicaron el trabajo de las fundaciones y organizaciones no gubernamentales y, por tanto, tuvo que ver con la creación de los huertos urbanos comunitarios que ellas gestionan. Por lo mismo, los mercados de trueque se vieron también impulsados.

El mayor desarrollo de las PEA a raíz de la crisis del 2008 hace pensar que los movimientos sociales de nuevo cuño que convergieron en el movimiento 15M han jugado algún papel en ello. Efectivamente, hay una vinculación concreta y directa de la moneda social y del centro social autogestionado Luis Buñuel con militantes activos del movimiento 15M. Las demás están ligadas a movimientos sociales de origen anterior, pero el $15 \mathrm{M}$ les dio un nuevo impulso, 
claramente manifiesto en la acción de los CSA, que organizan y ofrecen su sede a algunas de ellas.

\subsection{Inserción de las prácticas económicas alternativas en las políticas urbanas}

El Ayuntamiento de Zaragoza está adherido al Pacto por una Política Alimentaria Urbana (Milan Urban Food Policy Pact, 2015), firmado por un centenar de gobiernos locales, y participa en el programa europeo Life (European Commission, 2019). En este contexto viene desarrollando actuaciones en el terreno de la agroecología, siguiendo dos líneas complementarias: la primera es la recuperación para la agricultura de espacios no urbanizables insertos en el espacio urbano y su periferia inmediata, en la línea de lo que hacen otros ayuntamientos, como el de Valencia (Farinós et al., 2018), acompañada del apoyo a la transformación ecológica de tierras cultivadas. La ciudad disponía en el pasado de una extensa huerta, que se fue transformando en un gran alfalfar, en el clásico proceso de conversión a cultivos más extensivos -e incluso al abandono en forma de barbechos sociales- derivado de la expansión del espacio urbanizado. El ayuntamiento, por medio de los programas Life y Agros, está intentando recuperar la huerta tradicional, con métodos de cultivo ecológico, para lo cual ha creado y gestionado el "Banco de Tierras Huertas Km O". La segunda línea es la potenciación del comercio de proximidad de productos ecológicos, mediante la reserva de algunos espacios en los mercados de titularidad municipal. Los huertos urbanos comunitarios y el mercado agroecológico, en los que el Ayuntamiento juega un papel central, forman parte de esa política local, que se complementa con el mantenimiento de la red de huertos escolares de la ciudad.

Las PEA agroecológicas de Zaragoza no funcionan de forma integrada, como ya se ha dicho; su integración podría venir de la mano de una inserción más profunda en esos programas municipales de mayor alcance. En todo caso el Ayuntamiento parece estar jugando un papel activo en la construcción de un sistema alimentario alternativo, que, como señalan algunos autores (Méndez \& Monteserín, 2017; Michelini et al, 2017), no sería posible sin el apoyo de la administración local.

Respecto a las monedas comunitarias, el Ayuntamiento fue impulsor del banco de tiempo y lo apoya financieramente desde el mismo momento de su creación. Son numerosos los bancos de tiempo que cuentan con apoyo municipal en España (Valor \& Papaoikonomou, 2016; Pariza el al., 2014; Climent \& Lardiés, 2019a) y en otros países, donde se valoran como herramientas útiles para promover la inclusión social y el sentido de comunidad (Seyfang, 2004), constituyendo buenos ejemplos de colaboración público-privada. 
La firma de un convenio entre el gobierno municipal de Zaragoza en Común y el CSA Luis Buñuel va en la misma línea que las "Directrices para la cesión de espacios a entidades ciudadanas", que aprobó el Ayuntamiento de Madrid en el gobierno de la coalición Madrid en Común (Méndez \& Monteserín, 2019).

La coincidencia del CSA "Luis Buñuel" y del huerto urbano "El Gancho" en el mismo barrio lleva a una reflexión sobre el papel de las PEA en la rehabilitación urbana. El barrio de San Pablo -también conocido como El Gancho- es un ensanche medieval de la ciudad de Zaragoza, que sufrió un intenso proceso de degradación a lo largo del siglo XX. La actuación de los sucesivos ayuntamientos constitucionales ha ido revirtiendo poco a poco la situación, pero el proceso es muy lento y todavía queda mucho por hacer. Recientemente han surgido entidades vecinales, como Plataforma de Afectados del Gancho y Calles dignas, que reclaman medidas contra la inseguridad (tráfico de drogas) y la degradación física del barrio (solares) a la vez que alertan sobre la subida del precio de la vivienda y el riesgo de que se produzca un abandono de los actuales propietarios y un proceso de gentrificación con tintes especulativos como el que se ha visto en otras ciudades. De ahí la importancia de mantener el tejido social del barrio mediante planes de rehabilitación. En este contexto, potenciar prácticas alternativas puede ser una estrategia útil. Por ejemplo, la reconversión de solares vacíos en huertos urbanos y de edificios abandonados en centros sociales y lugares de convivencia, como se ha hecho en el barrio de San Pablo de Zaragoza. Por tanto, cabe concebir el análisis de las PEA también desde el punto de vista de la planificación urbana, física y social, pues pueden ayudar a que el tejido y las redes sociales de los barrios sobrevivan y prosperen, como se ha puesto de manifiesto también en otros entornos, como el barrio del Oeste de Salamanca (Sánchez et al., 2017).

\section{Conclusión}

Desde que se generalizaron las políticas neoliberales, a partir de los años ochenta del siglo XX, fueron surgiendo en los países occidentales prácticas económicas alternativas a las propias del sistema, mostrando una notable diversificación. Algunas de ellas -en las que se ha centrado este estudio- se desarrollan a escala local mediante procedimientos muy alejados de los típicos del mercado. La proximidad espacial, el contacto directo entre los actores y la apuesta por los circuitos cortos, sin intermediarios, son elementos esenciales de dichas prácticas. Varias de ellas están integradas en redes, que en algunos casos tienen alcance internacional, como la plataforma Community Exchange System, a la que se adhirió la moneda social Ebro; los grupos de consumo agroecológico, por su parte, forman una red ("Eco Red") de escala regional, junto 
con agricultores y artesanos, y los mercadillos de trueque otra de escala local. Se trata en todos los casos de redes de coordinación e intercambio de información, pero cada práctica concreta desarrolla su actividad de forma independiente en su ámbito local.

Su alejamiento respecto de las prácticas capitalistas convencionales queda atestiguado por el autoconsumo y la gestión comunitaria de los huertos, la relación directa productor-consumidor y el establecimiento de un precio justo en los grupos de consumo, el rechazo al dinero convencional en las monedas comunitarias o la gratuidad de los servicios y la gestión comunitaria de los bienes públicos por parte de los centros sociales autogestionados. Ese alejamiento de las prácticas convencionales plantea a estas PEA desafíos y problemas e impone límites a su funcionamiento. Estas prácticas vienen desarrollándose desde la década de los noventa, dándose la mayor proliferación a raíz de la crisis del 2008.

Quienes participan en Las PEA analizadas en este estudio de caso son una minoría de la población, pero forman un colectivo socialmente diverso, en el que predominan los trabajadores en activo con elevados niveles de formación e ingresos. Defienden unos valores diferentes de los del sistema vigente, frente al que mantienen una actitud crítica, y están comprometidos en movimientos sociales de base muy activos, especialmente los relacionados con el movimiento $15 \mathrm{M}$.

Las PEA emanan de dichos movimientos sociales o entroncan con ellos. Su presencia en la ciudad es muy pequeña y no es realista pensar que puedan provocar una transformación radical de la base económica. Lo mismo cabe decir respecto al espacio que construyen: igual que en el caso de Valladolid "no deja de ser un contrapunto marginal al generado por los actores principales que operan en la producción del espacio urbano" (Pascual et al., 2018, p. 214). No se puede ignorar que los movimientos sociales "dada la altamente individualizada estructura de la sociedad contemporánea, están experimentando dificultades para construir lazos fuertes y duraderos de solidaridad y cooperación entre la gente, lazos de unión que constituyen un recurso fundamental para la acción colectiva" (D'Alisa et al., 2015, p. 330). Por eso una de las preocupaciones expresadas por los responsables de las PEA estudiadas es la de construir o reforzar lazos interpersonales que den cohesión a la comunidad.

No obstante, no conviene subestimar su capacidad de influir positivamente en la difusión de valores en auge, como la sostenibilidad ambiental y la solidaridad social. La amplia dispersión de las PEA en el espacio urbano, unida a la diversidad de quienes participan en ellas, hace posible que desempeñen el papel de fermento para el cambio social: "ahora se reconoce que 
los movimientos de base, unidos en complejas relaciones con, y a veces en oposición a, los actores 'convencionales' gubernamentales y corporativos, pueden tener un poder transformador" (Feola \& Butt, 2017, p. 16).

Precisamente un punto fuerte de dichas prácticas, en el caso de Zaragoza, es que han contado y cuentan con el apoyo del Ayuntamiento prácticamente desde sus inicios. Eso marca una clara diferencia con otros casos, como Madrid (Méndez \& Monteserín, 2019) y Valencia (Salom et al., 2019), en los que el apoyo municipal se ha dado con los llamados "ayuntamientos del cambio", pero no antes ni después, en que esas ciudades fueron gobernadas por el Partido Popular.

Agradecimientos: Este artículo se integra en el proyecto de investigación "Espacios y prácticas económicas alternativas para la construcción de la resiliencia en las ciudades españolas" (20162018); Programa Estatal de Investigación, Desarrollo e Innovación Orientada a los Retos de la Sociedad, financiado por el Ministerio de Economía y Competitividad y el Fondo Europeo de Desarrollo Regional (FEDER); referencia CSO2015-65452-R (MINECO/FEDER).

Declaración responsable: Las/os autoras/es declaran que no existe ningún conflicto de interés con relación a la publicación de este artículo. Los tres autores han participado en la organización y redacción del mismo, asumiendo cada uno de manera más específica las siguientes tareas: $E$. Climent y R. Lardiés la revisión bibliográfica, el trabajo de campo y el análisis; S. Esteban la transcripción de las entrevistas, la elaboración de la base de datos y la cartografía. 


\section{Bibliografía}

Argueta-Prado, J.Q., \& Cortez-Noyola, M. (2016). Trueque, intercambio y reciprocidad: economía solidaria en las comunidades purépecha de Michoacán. Etnobiologia, (14), 79-89. Retrieved from https://revistaetnobiologia.mx/index.php/etno/article/view/294/293

Benito del Pozo, P., \& López-González, A. (2020). Urban resilience and the alternative economy: a methodological approach applied to northern Spain. Geographical Review, (110), 322-340. https://doi.org/10.1080/00167428.2019.1684195

Cahn, E., \& Gray, C. (2015). The time bank solution. Stanford Social Innovation Review, (13), 4045. https://ssir.org/articles/entry/the_time_bank_solution

Caravaca-Barroso, I., \& González-Romero, G. (2019). Una mirada alternativa al desarrollo local. Las monedas sociales en la aglomeración urbana de Sevilla. Scripta Nova, XXIII(621). https://doi.org/10.1344/sn2019.23.22487

Climent-López, E., \& Lardiés-Bosque, R. (2019a). Los bancos de tiempo y la reproducción de comunidad a escala local. In J.L. Sánchez-Hernández (Coord.), Espacios y prácticas económicas alternativas en las ciudades españolas (pp. 125-143). Aranzadi.

Climent-López, E., \& Lardiés-Bosque, R. (2019b). Los 'bancos de tiempo' como herramienta para afrontar la desigualdad y la vulnerabilidad social. Una mirada desde Zaragoza. In J.A. NietoCalmaestra \& C. Egea-Jiménez (Coord.), Colectivos en desventaja social y habitacional. La geografía de las desigualdades (pp. 69-82). Universidad de Granada.

Collom, E. (2008). Engagement of the Elderly in Time Banking. The Potential for Social Capital Generation in an Aging Society. Journal of Aging \& Social Policy, (20), 414436. https://doi.org/10.1080/08959420802186282

Conill, J., Cárdenas, A., Castells, M., Hlebik, S., \& Servon, L. (2012). Otra vida es posible. Prácticas económicas alternativas durante la crisis. UOC.

D'Alisa, G., Forno, F., \& Maurano, S. (2015). Grassroots (economic) activism in times of crisis. Mapping the redundancy of collective actions. Partecipazione e Conflitto, (8), 328342. https://doi.org/10.1285/i20356609v8i2p328

Díaz, F., Lourés, M.l., \& Pradel, M. (2018). Transformando los modelos de crecimiento y cohesión: cambios en la gobernanza de Barcelona y Madrid. EURE, (131), 173191. https://doi.org/10.4067/s0250-71612018000100173 
Dieste, J., \& Pueyo, A. (2003). Procesos de regeneración en el espacio urbano por las iniciativas de autogestión y okupación. Scripta Nova, VII(146). http://www.ub.edu/geocrit/sn/sn$\underline{146(108) \cdot h+m}$

Espinosa-Seguí, A. (2019). El papel de los grupos de consumo agroecológico en la construcción de un sistema de distribución y un orden alimentario alternativos. In J.L. Sánchez-Hernández (Coord.), Espacios y prácticas económicas alternativas en las ciudades españolas (pp. 65-85). Aranzadi.

Espinosa Seguí, A., Lardiés Bosque, R., \& Monteserín Abella, O. (2020). Mercados de productores agroecológicos en España. Venta directa y local en un nuevo escenario de relaciones de consumo. In J. Farinós Dasí (Coord.), J. Escribano, M ${ }^{a}$ P. Peñarrubia, J. Serrano \& S. Asins (Eds.), Desafíos y oportunidades en un mundo en transición. Una interpretación desde la Geografía (pp. 301-311). Tirant Humanidades, Univesitat de Valencia.

European Commission (2019). LIFE Programme In European

Commission. https://ec.europa.eu/easme/en/life

Farinós i Dasí, J., Peiró, E., Lloret-Gual, P., \& Vílchez-Muñoz, A. (2018). L'Horta, agricultura y ciudad: historia y presente. Valencia capital mundial de la alimentación en 2017. Ería: Revista cuatrimestral de geografía, (38), 287-305. https://doi.org/10.17811/er.3.2018.287-305

Feola, G., \& Butt, A. (2017). The diffusion of grassroots innovations for sustainability in Italy and Great Britain: an exploratory spatial data analysis. The Geographical Journal, (183), 1633. https://doi.org/10.1111/geoj.12153

Fernández, A., \& Miró, I. (2016). L'economia social i solidària a Barcelona. Ajuntament de Barcelona.

Fickey, A., \& Hanrahan, K.B. (2014). Moving beyond Neverland: reflecting upon the state of the diverse economies research program and the study of alternative economic spaces. ACME: An International E-Journal for Critical Geographies, (13), 394-403. https://acmejournal.org/index.php/acme/article/view/1013

García, M., Eizaguirre, S., \& Pradel, M. (2015). Social innovation and creativity in cities: A socially inclusive governance approach in two peripheral spaces of Barcelona. City, Culture and Society, (6), 93-100. https://doi.org/10.1016/j.ccs.2015.07.001

Gibson-Graham, J.K. (2008). Diverse economies: performative practices for 'other worlds'. Progress in Human Geography, (32), 613-632. https://doi.org/10.1177/0309132508090821 
Gómez-Gonçalvez, A. (2019). Huertos urbanos: laboratorios para la enseñanza y el aprendizaje práctico de la alternatividad. In J.L. Sánchez-Hernández (Coord.), Espacios y prácticas económicas alternativas en las ciudades españolas (pp. 87-106). Aranzadi.

Gonick, S. (2016). Indignation and inclusion: Activism, difference, and emergent urban politics in postcrash Madrid. Environment and Planning D: Society and Space, (34), 209226. https://doi.org/10.1177/0263775815608852

González, R., Martínez, M.A., \& Barranco, O. (2018). Autogestión de equipamientos y espacios urbanos: los centros sociales okupados y autogestionados. In P. Ibarra, R. Gomà, S. Martí \& R. González (Coord.), Movimientos sociales y derecho a la ciudad. Creadores de democracia radical (pp. 88-102). Icaria.

González-Romero, G., \& Torres-Gutiérrez, F.J. (2019). Dimensión territorial y caracteres socioespaciales de las prácticas económicas alternativas. Aproximación a partir del análisis comparado de casos. In J.L. Sánchez-Hernández (Coord.), Espacios y prácticas económicas alternativas en las ciudades españolas (pp. 257-276). Aranzadi.

González-Romero, G., Torres-Gutiérrez, F.J., \& Caravaca-Barroso, I. (2019). Cuestionando el sistema financiero global: experiencias de monedas sociales en España. In J.L. SánchezHernández (Coord.), Espacios y prácticas económicas alternativas en las ciudades españolas (pp. 107-124). Aranzadi.

Green Guerrillas (2019). Our history. In Green Guerrillas. http://www.greenguerillas.org/

Harcourt, W. (2014). The future of capitalism: a consideration of alternatives. Cambridge Journal of Economics, (37), 1307-1328. https://doi.org/10.1093/cje/bet048

Hillebrand, S., \& Zademach, H. (2014). Alternative economies and spaces: introductory remarks In H. Zademach \& S. Hillebrand, Alternative Economies and Spaces: New Perspectives for a Sustainable Economy (pp. 10-22). Bielefeld: transcript Verlag. https://doi.org/10.14361/transcript.9783839424988

Kirwan, J. (2006). The interpersonal world of direct marketing: examining conventions of quality at UK farmers' market. Journal of Rural Studies, (22), 301 312. https://doi.org/10.1016/j.jrurstud.2005.09.001

Kousis, M., \& Paschou, M. (2017). Alternative forms of resilience. A typology of approaches for the study of citizen collective responses in hard economic times. Partecipazione e Conflitto, (10), 136-168. https://doi.org/10.1285/i20356609v10i1p135 
Larrubia Vargas, R., Natera Rivas, J. J., \& Carruana Herrera, D. (2020). Los huertos urbanos como estrategia de transición urbana hacia la sostenibilidad en la ciudad de Málaga. Boletín de la Asociación de Geógrafos Españoles, (86). https://doi.org/10.21138/bage.2972

Leyshon, A., \& Lee, R. (2003). Introduction: alternative economic geographies. In A. Leyshon, R. Lee \& C. Williams (Coord.), Alternative Economic Spaces. Sage. https://doi.org/10.4135/9781446220825.n1

Llobera, P. (2013). Iniciativas de re-comunitarización y des-mercantilización en la ciudad. Documentación Social, (168), 135-158.

López-García, D. (2015). Producir alimentos, reproducir comunidad. Redes alimentarias alternativas como formas económicas para la transición social y ecológica. Libros en Acción.

López-González, A., \& Benito del Pozo, P. (2019). Los factores y límites de las prácticas económicas alternativas en León y Oviedo. In J.L. Sánchez-Hernández (Coord.), Espacios y prácticas económicas alternativas en las ciudades españolas (pp. 209-229). Aranzadi.

Markkanen, S., \& Burgess, G. (2015): Introduction to time banking and time credits. Cambridge Centre for Housing and Planning Research.

Martínez López, M. (2003). Viviendas y centros sociales en el movimiento de okupación: entre la autogestión doméstica y la reestructuración urbana. Scripta Nova, VII (146). http://www.ub.edu/geocrit/sn/sn-146(109).htm

Mauldin, R.L. (2015). Local currency for community development: policy barriers and support. Journal of Community Practice,

(23), $462-$ 476. https://doi.org/10.1080/10705422.2015.1091420

Mauleón Gómez, J.R. (2012). Mercados de agricultores en España: diagnóstico y propuesta de actuación. Ager, (13), 53-84. https://www.redalyc.org/articulo.oa?id=29624436002

Méndez, R. (2015). Redes de colaboración y economía alternativa para la resiliencia urbana: una agenda de investigación. Biblio3W, XX(1139). http://www.ub.edu/geocrit/b3w-1139.pdf

Méndez, R. (2018). Redes económicas alternativas ¿para una sociedad postcapitalista? Algunas experiencias en Madrid. In Las ciencias sociales y la edificación de una sociedad post-capitalista (pp. 1-22). XV Coloquio Internacional de Geocrítica. Universidad de Barcelona, May 712. http://www.ub.edu/geocrit/XV-Coloquio/RicardoMendez.pdf 
Méndez-Gutiérrez del Valle, R., \& Monteserín Abella, O. (2017). Redes alimentarias alternativas en grandes ciudades: los mercados de productores agrarios en Madrid. Cuadernos Geográficos, (56), 193-216.

https://revistaseug.ugr.es/index.php/cuadgeo/article/view/4049/5315

Méndez-Gutiérrez del Valle, R., \& Monteserín Abella, O. (2019). Prácticas económicas alternativas en Madrid: una aproximación. In J.L. Sánchez-Hernández (Coord.), Espacios y prácticas económicas alternativas en las ciudades españolas (pp. 147-164). Aranzadi.

Mercados de trueque en Zaragoza (n.d.). http://truequezaragoza.blogspot.com/

Michelini, J.J., Méndez-Gutiérrez del Valle, R., \& Abad Aragón, L.D. (2017) Movilización social y alternativas alimentarias en áreas urbanas: los grupos de consumo agroecológico en Madrid. Ciudad y Territorio. Estudios Territoriales, (194), 679698. https://recyt.fecyt.es/index.php/CyTET/article/view/76589

Milan Urban Food Policy Pact (2015). Pacto de política alimentaria urbana de Milán. In Milan Urban Food Policy Pact. http://www.foodpolicymilano.org/wpcontent/uploads/2015/10/Milan-Urban-Food-Policy-Pact-_SPA.pdf

Moro-Gutiérrez, L., \& Lamarque, M. (2019). El estudio de las prácticas económicas alternativas a través de una metodología multitécnica. In J.L. Sánchez-Hernández (Coord.), Espacios y prácticas económicas alternativas en las ciudades españolas (pp. 299-317). Aranzadi.

North, P. (2005). Scaling alternative economic practices? Some lessons from alternative currencies. Transactions of the Institute of British Geographers, (30), 221 233. https://doi.org/10.1111/j.1475-5661.2005.00162.x

Pariza, J., García, A., Fuentes, S., \& Iñarra, J. (2014). El banco de tiempo de Barakaldo. La comunidad como alternativa. Arbela: Hezkuntza aldizkaria, (46), 4346. https://sites.google.com/a/bgune04.net/arbela/arbela-46

Pascual Ruiz-Valdepeñas, H., Gil Álvarez, E., \& Guerra Velasco, J.C. (2018). Práctica social, economía alternativa y espacios de proximidad en la ciudad de Valladolid. Recerca, Revista de Pensament i Anàlisi, (23), 193-218. https://doi.org/10.6035/recerca.2018.23.9

REC Moneda Ciutadana (2019). Empieza en el barrio. Cambia la ciudad In REC Barcelona. Recurso Económico Ciudadano. https://rec.barcelona/es/inicio 
Rice, J. (2014). A counter-hegemonic discourse of economic difference: A critical discourse analysis of timebanking in the United States. International Journal of Community Currency Research, (18), 1-10. http://dx.doi.org/10.15133/j.ijccr.2014.001

Salom, J., Pitarch, M.D., \& Sales, A. (2017). Innovación social: estrategias urbanas en un contexto de cambio. El caso de la ciudad de Valencia. CIRIEC-España. Revista de Economía Pública, Social y Cooperativa, (91), 31-58. https://doi.org/10.7203/ciriec-e.91.10451

Salom Carrasco, J., Pitarch Garrido, M.D., Sales Ten, A., \& Cornadó Camí, M. (2019). Prácticas económicas alternativas e innovación social: el caso de la ciudad de Valencia. In J.L. SánchezHernández (Coord.), Espacios y prácticas económicas alternativas en las ciudades españolas (pp. 165-184). Aranzadi.

Sánchez, J.L., Penela, A., Alonso, J.L., \& Moro, L. (2017). Regeneración urbana, innovación social y prácticas económicas alternativas en ciudades medias: el barrio del Oeste (Salamanca). Ería. Revista Cuatrimestral de Geografía, XXXVII, 6782. https://doi.org/10.17811/er.1.2017.67-82

Sánchez-Hernández, J.L. (2019). Espacios y prácticas económicas alternativas en las ciudades españolas. Aranzadi.

Sánchez-Hernández, J.L., \& Glückler, J. (2019). Alternative economic practices in Spanish cities: from grassroots movements to urban policies? An institutional perspective. European Planning Studies, (27), 2450-2469. https://doi.org/10.1080/09654313.2019.1644295

Sánchez-Hernández, J.L., \& Espinosa-Seguí, A. (2020). ¿Alternativa o adaptación? Los grupos de consumo de alimentos ecológicos en el área urbana de Alicante. Scripta Nova. Revista Electrónica Geografía y Ciencias Sociales, XXIV, (638). https://doi.org/10.1344/sn2020.24.27056

Sanz Casas, G. (2002). Las asociaciones de banco de tiempo: entre la reciprocidad y el mercado. Éndoxa: Series Filosóficas, (15), 153164. https://doi.org/10.5944/endoxa.15.2002.5042

Seyfang, G. (2004). Time Banks: rewarding community self-help in the inner city? Community Development Journal, (39), 62-71. https://doi.org/10.1093/cdj/39.1.62

Subirats, J., \& García-Bernardos, A. (2015). Innovación social y políticas urbanas en España. Experiencias significativas en las grandes ciudades. Icária. 
Valor-Martínez, C., \& Papaoikonomou, E. (2016). Time banking in Spain. Exploring their structure, management and users' profile. Revista internacional de sociología, (74). https://doi.org/10.3989/ris.2016.74.1.028

White, R.J., \& Williams, C.C. (2012). The Pervasive Nature of Heterodox Economic Spaces at a Time of Neoliberal Crisis: Towards a "Postneoliberal" Anarchist Future. Antipode, (44), 16251644 https://doi.org/10.1111/j.1467-8330.2012.01033.x

Yates, L. (2015). Everyday politics, social practices and movement networks: Daily life in Barcelona's social centres. The British Journal of Sociology, (66), 236258. https://doi.org/10.1111/1468-4446.12101 